\title{
Uncertainty of eddy covariance flux measurements over an urban area based on two towers
}

\author{
Leena Järvi ${ }^{1,2}$, Üllar Rannik ${ }^{1}$, Tom V. Kokkonen ${ }^{1}$, Mona Kurppa ${ }^{1}$, Ari Karppinen ${ }^{3}$, Rostislav D. Kouznetsov ${ }^{3,4}$, \\ Pekka Rantala ${ }^{1}$, Timo Vesala ${ }^{1,5}$, and Curtis R. Wood ${ }^{3}$ \\ ${ }^{1}$ Institute for Atmospheric and Earth System Research (INAR)/Physics, Faculty of Science, University of Helsinki, P.O. Box \\ 68, 00014 Helsinki, Finland \\ ${ }^{2}$ Helsinki Institute of Sustainability Science, Faculty of Science, University of Helsinki, P.O. Box 68, 00014 Helsinki, Finland \\ ${ }^{3}$ Finnish Meteorological Institute, P.O. Box 503, 00101 Helsinki, Finland \\ ${ }^{4}$ A. M. Obukhov Institute of Atmospheric Physics, 119017 Moscow, Russia \\ ${ }^{5}$ INAR/Forest Sciences, Faculty of Agriculture and Forestry, P.O. Box 27, 00014 University of Helsinki, Finland
}

Correspondence: Leena Järvi (leena.jarvi@helsinki.fi)

Received: 22 March 2018 - Discussion started: 22 May 2018

Revised: 14 August 2018 - Accepted: 6 September 2018 - Published: 2 October 2018

\begin{abstract}
The eddy covariance (EC) technique is the most direct method for measuring the exchange between the surface and the atmosphere in different ecosystems. Thus, it is commonly used to get information on air pollutant and greenhouse gas emissions, and on turbulent heat transfer. Typically an ecosystem is monitored by only one single EC measurement station at a time, making the ecosystem-level flux values subject to random and systematic uncertainties. Furthermore, in urban ecosystems we often have no choice but to conduct the single-point measurements in non-ideal locations such as close to buildings and/or in the roughness sublayer, bringing further complications to data analysis and flux estimations. In order to tackle the question of how representative a single EC measurement point in an urban area can be, two identical EC systems - measuring momentum, sensible and latent heat, and carbon dioxide fluxes - were installed on each side of the same building structure in central Helsinki, Finland, during July 2013-September 2015. The main interests were to understand the sensitivity of the vertical fluxes on the single measurement point and to estimate the systematic uncertainty in annual cumulative values due to missing data if certain, relatively wide, flow-distorted wind sectors are disregarded.

The momentum and measured scalar fluxes respond very differently to the distortion caused by the building structure. The momentum flux is the most sensitive to the measurement location, whereas scalar fluxes are less impacted. The
\end{abstract}

flow distortion areas of the two EC systems (40-150 and $230-340^{\circ}$ ) are best detected from the mean-wind-normalised turbulent kinetic energy, and outside these areas the median relative random uncertainties of the studied fluxes measured by one system are between $12 \%$ and $28 \%$. Different gapfilling methods with which to yield annual cumulative fluxes show how using data from a single EC measurement point can cause up to a $12 \%\left(480 \mathrm{~g} \mathrm{C} \mathrm{m}^{-2}\right)$ underestimation in the cumulative carbon fluxes as compared to combined data from the two systems. Combining the data from two EC systems also increases the fraction of usable half-hourly carbon fluxes from $45 \%$ to $69 \%$ at the annual level. For sensible and latent heat, the respective underestimations are up to $5 \%$ and $8 \%$ $\left(0.094\right.$ and $\left.0.069 \mathrm{TJ} \mathrm{m}^{-2}\right)$. The obtained random and systematic uncertainties are in the same range as observed in vegetated ecosystems. We also show how the commonly used data flagging criteria in natural ecosystems, kurtosis and skewness, are not necessarily suitable for filtering out data in a densely built urban environment. The results show how the single measurement system can be used to derive representative flux values for central Helsinki, but the addition of second system to other side of the building structure decreases the systematic uncertainties. Comparable results can be expected in similarly dense city locations where no large directional deviations in the source area are seen. In general, the obtained results will aid the scientific community by pro- 
viding information about the sensitivity of EC measurements and their quality flagging in urban areas.

\section{Introduction}

It is recommended that surface fluxes measured using the eddy covariance (EC) technique are done in the inertial sublayer and free from obstructions (Roth, 2000). These assumptions are often easy to meet over natural surfaces but can be challenging for EC systems above cities. Often the EC measurements are made within or in the vicinity of the roughness sublayer, the adjacent layer to the surface with height of 2-5 times the mean building height (Raupach et al., 1991). In this layer, turbulence is not homogeneous but rather varies greatly in space, and the Monin-Obukhov similarity theory (MOST) is no longer strictly valid. Despite the non-ideal conditions, EC measurements from urban areas are needed for the purposes of wind engineering, understanding the urban surfaceatmosphere interactions, in the estimation of urban carbon budgets (Christen et al., 2011; Nordbo et al., 2012a), and in order to improve the description of urban areas in numerical weather and air quality predictions via the measured turbulent fluxes of heat (Grimmond et al., 2010; Karsisto et al., 2015; Demuzere et al., 2017). In order for the urban EC systems to meet the requirements of the technique, we are often forced to conduct the measurements on top of buildings or other platforms such as telecommunication towers (Wood et al., 2010; Liu et al., 2012; Brümmer et al., 2013; Nordbo et al., 2013; Keogh et al., 2012; Ao et al., 2016) instead of narrow lattice masts, which would minimise the effect of the structure itself on the EC measurements. Thus strictly speaking, the measurements are not necessarily made completely free of the impact of roughness elements even if the measurement height is sufficiently above the surrounding roughness elements. The interaction between the EC measurements and the measurement platform itself causes challenges for obtaining high-quality EC data sets, and special attention should be paid to the effect of the so-called flow distortion area on the measurements (Barlow et al., 2011). Urban EC measurements have furthermore raised the need for local scaling of mean turbulent properties with minor deviations from inertial-sublayer scaling (Rotach, 1993; Roth, 2000; Vesala et al., 2008; Wood et al., 2010) and corrections for local-scale anthropogenic sources (Kotthaus and Grimmond, 2012).

The basic-quality screening of a single sensor in measuring vertical fluxes can be performed based on the vertical deflection angles and expected turbulence, and sometimes even by simply disregarding whole (flow-distorted) wind sectors (Barlow et al., 2011). It is not however ideal if we have to reject a relatively large fraction of the data. For cumulative emission estimates, the flux data need to be gap-filled - but in urban areas this is more complex than in vegetated environments due to the large amount of explanatory variables and the high spatial variability of the sources and sinks (Menzer et al., 2015). The gap-filling methods used in urban EC flux data sets vary from simple look-up tables to artificial neural networks (Schmidt et al., 2008; Kordowski and Kuttler, 2010; Christen et al., 2011; Järvi et al., 2012), but the more complex and time-demanding solutions might not always be considerably better than the more simple ones. Järvi et al. (2012) found only a $4 \%$ difference in cumulative carbon dioxide $\left(\mathrm{CO}_{2}\right)$ fluxes when utilising median diurnal cycles and neural networks in filling data gaps at a semi-urban site in Helsinki. On top of that, any statistical gap-filling techniques can be biased if certain wind directions are compromised above heterogeneous surfaces, and therefore single-point EC measurements might not give realistic cumulative flux values. The same applies to the representativeness of a single measurement point for a studied ecosystem in general. Already at forested sites, which are generally considered to be easier for EC measurements than urban areas, the uncertainties in $\mathrm{CO}_{2}$ flux originating from a single measurement point have been reported to be $6 \%$ (Hollinger et al., 2012). In the past, simultaneous observations from more than one EC station have been used to estimate uncertainties in EC-measured fluxes above vegetated surfaces (Hollinger and Richardson, 2005; Kessomkiat et al., 2010; Peltola et al., 2015; Post et al., 2015), but in urban areas no estimations have been derived from direct EC measurements with more than one measurement system at the same level.

The aim of this work is twofold. Firstly, we want to examine the sensitivity of a single-point EC system in measuring the vertical fluxes of momentum, sensible and latent heat, and carbon dioxide in a highly dense urban area. Secondly, we want to understand what the implication is of the nonideal measurement location and resulting data removal on the calculation of cumulative fluxes, which are important for emission-inventory comparison and planning of neighbourhoods. These two aims will be examined with the aid of two identical EC measurement systems located on the opposite sides of a bluff-body tower in the centre of Helsinki.

\section{Methods}

\subsection{Measurement site and instrumentation}

The measurements were conducted in central Helsinki (Fig. 1), where two identical EC setups were installed on top of a hotel building (Fig. 2) at a height ( $z$ ) of $60 \mathrm{~m}$ above the ground during July 2013 until September 2015. Within a $1 \mathrm{~km}$ radius of the measurement location, $37 \%$ of the surface is covered with buildings and $41 \%$ with paved surfaces, leaving only $22 \%$ of the surface covered with vegetation (Nordbo et al., 2015). The surrounding buildings are fairly uniform with a mean height of $24 \mathrm{~m}$, displacement height of $15 \mathrm{~m}$ and aerodynamic roughness length of $1.4 \mathrm{~m}$ (Nordbo et al., 2013). However one notable exception is the Hotel 
Torni building itself: its main building is up to $15 \mathrm{~m}$ above the ground level, the tower up to $58 \mathrm{~m}$ and upper masonry extending up to $66 \mathrm{~m}$. The two EC systems (EC1 and EC2) were mounted on the opposite sides of an upper masonry on $2.3 \mathrm{~m}$ high measurement masts (Fig. 2). The systems are located at $60 \mathrm{~m}$, which is 2.5 times the mean building height, and therefore they should be above the roughness sublayer and blending height where local-scale surface sources and sinks have aggregated together (Raupach et al., 1991). The centre of Helsinki is located on a peninsula, but previous analyses on the source area of the EC1 system have shown the flux footprint to lie above the city and not the sea (Kurppa et al., 2015; Auvinen et al., 2017). The two systems have a separation distance of $10 \mathrm{~m}$ and thus measure virtually the same source area. The downside of the measurement location is that the upper masonry disturbs the flow, and we choose to neglect data for certain wind directions based on quality considerations. Based on the mean-wind-normalised turbulent kinetic energy (TKE), the areas are approximated to be 40150 and $230-340^{\circ}$ for EC1 and EC2, respectively (Fig. 3).

Each system comprised a 3-D ultrasonic anemometer measuring the sonic temperature and 3-D orthogonal wind speeds (USA-1, Metek GmbH, Germany), and an infrared gas analyser (LI-7200, LI-COR Biosciences, Lincoln, NE, USA) giving concentrations of water vapour and $\mathrm{CO}_{2}$. The air inlets were positioned $0.15 \mathrm{~m}$ below the anemometer centre, and air was drawn through a $1 \mathrm{~m}$ long stainless-steel tube (with inner diameter of $0.04 \mathrm{~m}$ ) to the gas analyser. The flow rates were $10 \mathrm{~L} \mathrm{~min}^{-1}$. Tubes were heated with a power of $9 \mathrm{~W} \mathrm{~m}^{-1}$ to avoid condensation of water vapour on their walls. The raw EC data were sampled with a frequency of $10 \mathrm{~Hz}$, from which the 30 min flux values were calculated using commonly accepted procedures (Nordbo et al., 2012b). The fluxes were determined using the maximum-covariance technique where the window mean and width for the lag time were identical for the two systems $\left(0-1.2 \mathrm{~s}\right.$ for $\mathrm{CO}_{2}$ and $0-7 \mathrm{~s}$ for $\left.\mathrm{H}_{2} \mathrm{O}\right)$. Before the calculation of the fluxes, data were despiked and linearly detrended. The high-response losses resulting from the tube attenuation were corrected with the aid of measured temperature cospectra, yielding a $\mathrm{CO}_{2}$ response time of $0.11 \mathrm{~s}$ for $\mathrm{EC} 1$ and $0.14 \mathrm{~s}$ for EC2. Wind coming from the flow distortion areas removed $27 \%$ of the EC1 data and $38 \%$ of the EC2 data. The larger fraction with EC2 is due to the prevailing wind direction from south to west.

\subsection{Data analysis}

In order to understand possible differences between the two measurement setups, several variables and statistics describing turbulence characteristics will be evaluated. Stationarity (FS), skewness (SK) and kurtosis $(K)$ are common variables used to examine the quality of EC data, with the first providing information about the stationarity of the flux measurements and the latter two providing information about the form of the probability function of the measured concentra- tion, temperature or wind speed (Vickers and Mahrt, 1997). Stationarity is calculated by dividing each $30 \mathrm{~min}$ flux period into six subsets for which the flux values are separately calculated and their mean furthermore compared with the $30 \mathrm{~min}$ flux values. Typically, with differences below $30 \%$, data are considered to be high quality and differences below $60 \%$ still suitable for general data analysis. In this study, the strict limit of $30 \%$ will be used. SK describes the asymmetry of the probability function of a variable and is calculated from

$\mathrm{SK}=\frac{\overline{\left(x^{\prime 3}\right)}}{\sigma_{x}^{3}}$,

where $x$ is a velocity or scalar variable, the overbar indicates the $30 \mathrm{~min}$ time average, the prime indicates the deviation from the mean of the variable and $\sigma_{x}$ is its standard deviation. SK between -2 and +2 is considered to be good-quality EC data. $K$ is a measure of sharpness of the probability function; i.e. its high values indicate peaks in the data. It is calculated from

$K=\frac{\overline{\left(x^{\prime 4}\right)}}{\sigma_{x}^{4}}$.

$K$ between 1 and 8 is considered as reasonable-quality data.

The relative random error (RRE) of the vertical flux of scalar $x\left(F=\overline{w^{\prime} x^{\prime}}\right.$, where $w$ is the vertical wind speed $)$ is calculated as the square root of the random error variance $\left(\sigma_{F}^{2}\right)$ normalised with the absolute value of the flux according to Lenschow et al. (1994):

$\operatorname{RRE}=\frac{\sigma_{F}(\Gamma)}{|F|}=\left(2 \mu_{\rho} \frac{\Gamma_{\rho}}{\Gamma}\right)^{1 / 2}$,

where $\rho$ refers to the instantaneous flux $\left(w^{\prime} s^{\prime}\right) . \mu_{\rho}$ is the flux variance:

$\mu_{\rho}=\mu_{w} \mu_{x}+F^{2}$,

where $\mu_{w}$ and $\mu_{x}$ are the variances of $w$ and $x, \Gamma$ is the averaging period $(30 \mathrm{~min})$, and $\Gamma_{\rho}$ is the integral timescale defined as the integral over the autocovariance function $\left(R_{\rho}\right.$; Rannik et al., 2016) and in practice is estimated as the lag when $R_{\rho}$ drops to $e^{-1}$.

The TKE is obtained from

$\mathrm{TKE}=0.5\left(\overline{u^{\prime 2}}+\overline{v^{2}}+\overline{w^{\prime 2}}\right)$.

The turbulent transfer efficiencies for momentum and heat fluxes are calculated from

$$
\begin{gathered}
\left|r_{u w}\right|=\frac{\overline{u^{\prime} w^{\prime}}}{\sigma_{u} \sigma_{w}}, \\
\left|r_{w T}\right|=\frac{\overline{w^{\prime} T^{\prime}}}{\sigma_{w} \sigma_{T}} .
\end{gathered}
$$




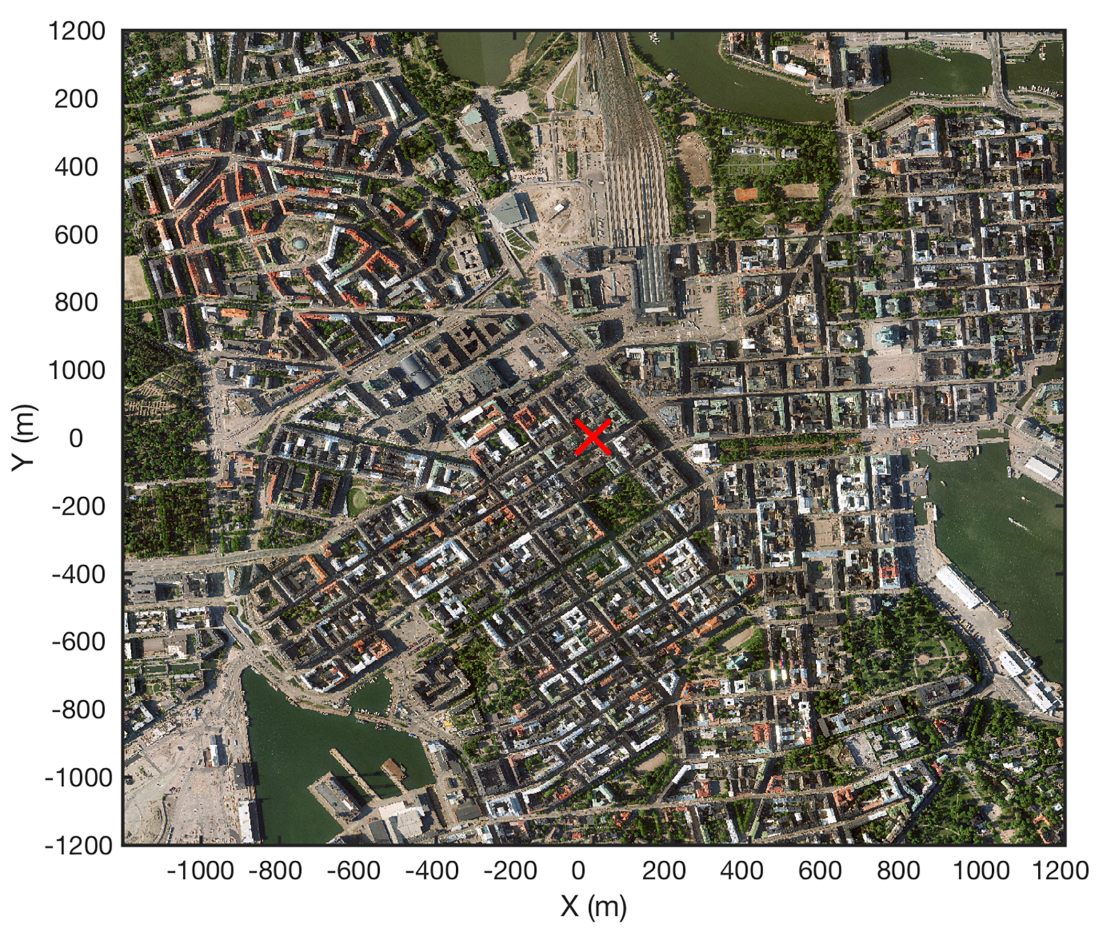

Figure 1. Aerial image of central Helsinki (Kaupunkimittausosasto, Helsinki, 2011). Hotel Torni is marked with a red cross.

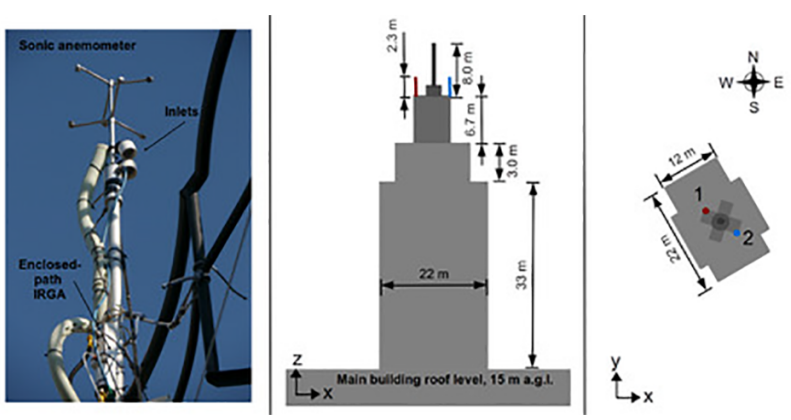

Figure 2. Left: a photo of one EC installation. Middle: a side view of the tower. Right: a plan view. See Nordbo et al. (2013) for more details.

The power and cospectra of momentum $(\tau)$, sensible heat $(H)$ and carbon dioxide $\left(F_{\mathrm{C}}\right)$ fluxes are calculated using fast Fourier transforms for $60 \mathrm{~min}$ periods ( $2^{15}$ points) using widely used procedures (Stull, 1998). Spectra are divided into 76 logarithmic, evenly spaced bins for which the mean values are calculated. The normalised forms for power spectra of the variable $x\left(S_{x}(f)\right)$ and cospectra between $w$ and $x$ $\left(S_{x w}(f)\right)$ are used, where they are multiplied by the measurement frequency $(f)$ and divided by variance $\left(\operatorname{var}(x)=\mu_{x}\right)$ and covariance $(\operatorname{cov}(x, w))$, according to

$$
\frac{f S_{x}(f)}{\operatorname{var}(x)}
$$

$$
\frac{f S_{x w}(f)}{\operatorname{cov}(x, w)}
$$

The normalised spectra and cospectra are plotted against the normalised frequency $n$ :

$$
n=\frac{f(z-d)}{U},
$$

where $U$ is the mean wind speed.

\section{Results}

\subsection{Turbulent transport and vertical fluxes}

The flow distortion areas of both EC systems (no filtering based on FS, SK and $K$ ) due to the upper masonry are clearly distinguishable from the vertical deflection angle $(\theta)$, normalised TKE and turbulent transfer coefficients (Fig. 3). Even though the two EC systems were, to the best of our ability, designed to be identical and symmetrically located on the opposite side of the masonry, we observe quantitative asymmetry in the first- and second-moment statistics. The vertical deflection angle, which sets $w=0$ in the twodimensional coordinate rotation $\left(\tan ^{-1}(\bar{w} / U)\right)$ and describes the distortion of the measurement structure on the measurements, experiences fluctuating behaviour in these areas, indicating modified flow structure due to the building masonry 
(Fig. 3a). Some of the deviation can be explained by variation in the surrounding topographies in the direction of flow distortion areas.

Outside the flow distortion areas, the vertical deflection angles vary between 5 and $18^{\circ}$ with $\mathrm{EC} 1$ and between 2 and $15^{\circ}$ with EC2, which are in the same range as observed at BT Tower in London (Barlow et al., 2011). The normalised TKE at the flow distortion area measured with $\mathrm{EC} 1$ reaches 2.5, while that measured with EC2 reaches 1.7, showing clearly the asymmetry in the areas. Both EC systems give a mean value of 0.34 for the normalised TKE outside the flow distortion areas, indicating that they measure similar turbulence (Fig. 3b). Furthermore, TKE is fairly uniform with wind direction despite the measurement location being considered to be complex from the point of view of micrometeorological measurements. Also the transfer efficiencies for heat are similar between the two systems with the values of 0.32 for EC1 and 0.29 for EC2 outside the flow distortion areas (Fig. 3c). The transfer efficiencies of momentum are clearly different from those of heat and have the largest deviations between the two systems (Fig. 3d). The transfer coefficient for heat has a clear dip when the flow is disturbed, whereas the momentum transfer coefficients follow a more complex pattern. This indicates the different effect of the measurement platform on the transport of momentum and heat, with a stronger effect on the former.

The asymmetry of the flow distortion areas is furthermore reflected in the vertical fluxes of momentum $(\tau)$, sensible $(H)$ and latent heat $(\mathrm{LE})$, and $\mathrm{CO}_{2}\left(F_{\mathrm{C}}\right)$ (Fig. 4). The strength of asymmetry varies with atmospheric stability and between variables, indicating that purely prevailing meteorology cannot be responsible for the observed differences but rather that the morphological effects play a role. Outside the flow distortion areas, differences between the two systems are small and depend on the studied flux. The best correlation between the two EC systems is seen in $H$, with the median of coefficient of determination $\left(R^{2}\right.$ calculated as the square of the Pearson correlation coefficient) being 0.95 , the slope of the linear least square regression $(\mathrm{EC} 2=$ slope $\cdot \mathrm{EC} 1+$ intercept $)$ being close to 1 and the intercept being within $\pm 5 \mathrm{~W} \mathrm{~m}^{-2}$ (Fig. 5). The maximum difference in the absolute values is $20 \mathrm{~W} \mathrm{~m}^{-2}$ (Fig. 4b) in unstable conditions. In the correlation of $\tau$, the largest differences of all fluxes with a sinusoidal pattern as a function of wind direction are seen. The slope varies between 0.5 and 1.8 , and the intercept is systematically below 0 , indicating lower momentum flux measured by the EC2 than EC1 (Fig. 5a, b). Furthermore, the median $R^{2}$ between the two measurement systems is 0.85 (Fig. 5c). The directional dependencies and correlations between the two systems in measuring LE and $F_{\mathrm{C}}$ follow a similar pattern, indicating similarity between the two variables (Figs. 4c, d and 5). For LE, the correlation statistics are however somewhat lower than for $F_{\mathrm{C}}$. LE has a coefficient of determination in the range of $0.6-0.9$, a slope in the range of $0.7-1.0$ and an intercept of the order of $10 \mathrm{~W} \mathrm{~m}^{-2}$, with a greater flux measured with EC2 than EC1. For $F_{\mathrm{C}}$ the respective values are $0.8-0.9,0.7-1.1$ and $0-5 \mu \mathrm{mol} \mathrm{m}{ }^{-2} \mathrm{~s}^{-1}$. The absolute differences yield $-1.9 \mathrm{~W} \mathrm{~m}^{-2}$ and $-0.3 \mu \mathrm{mol} \mathrm{m}{ }^{-2} \mathrm{~s}^{-1}$, respectively. The correlation statistics in our case are slightly poorer than observed over a a grassland in the UK (Mccalmont et al., 2017), where $R^{2}$ scatter suggested sampling uncertainty between $5 \%$ and $7 \%$ as compared to our $10 \%-20 \%$.

The separation distance between the two EC systems is less than $10 \mathrm{~m}$, and thus they are expected to measure the same source area outside the flow distortion areas. At the same time the observed differences cannot arise from the post-processing as fluxes were calculated and processed in a similar manner. Some of the difference can still originate from instrument drifting, but this would indicate nondirectional dependence. As a result, the differences in the fluxes measured by the two systems very probably relate to the variation of the flux field caused by complex terrain. In past studies above vegetated ecosystems, the random uncertainty of flux measurements resulting from instrumental errors, heterogeneity of the surface and turbulence has been determined using the so-called two-tower approach (Hollinger and Richardson, 2005; Kessomkiat et al., 2010). Its assumption is that the two time series should be independent from each other and thus cannot be used in our case when the two systems are measuring the same footprint. We can however still calculate the RRE in order to get an understanding about the random uncertainties of our EC measurements. Of all studied vertical fluxes, the largest random uncertainties relate to $\tau$ (medians between $23 \%$ and $28 \%$ ) and the lowest to daytime $H$ (medians $12 \%$ and $13 \%$ ) (Fig. 6). For $\tau$ no systematic pattern between daytime and night-time is seen, whereas for the other fluxes nocturnal uncertainties tend to be larger when the scalar fluxes are small. For fluxes other than momentum, RREs from EC2 are slightly larger than those from EC1, whereas for $\tau$ it is vice versa. The RREs are of the same order of magnitude as observed at the semi-urban site in Kumpula and above vegetated ecosystems. In these, however, the RRE associated with $\tau$ tends to be the lowest contrary to our study (Finkelstein and Sims, 2001; Billesbach, 2011; Nordbo et al., 2012b), which is because of the complex measurement location and source-sink distribution at our site.

Both statistical variables RRE and $R^{2}$ should theoretically be a measure of random uncertainty. When RREs measured with the two systems are larger, $R^{2}$ between the systems is expected to be smaller. Furthermore, we expected the two resulting uncertainty rankings (according to RRE and R2) across the different fluxes to be consistent. However, this is not observed, and based on $\mathrm{R}^{2}$ the fluxes can be ranked in increasing order LE, $F_{\mathrm{C}}, \tau$ and $H$ both in day- and night-time $(0.79,0.82,0.86,0.92$ and $0.66,0.85,0.88,0.94)$. A possible explanation for this is that $R^{2}$ is calculated between the two EC systems and is impacted by systematic disturbances and the building masonry. Thus, RRE is considered to be more representative for flux random uncertainties. 

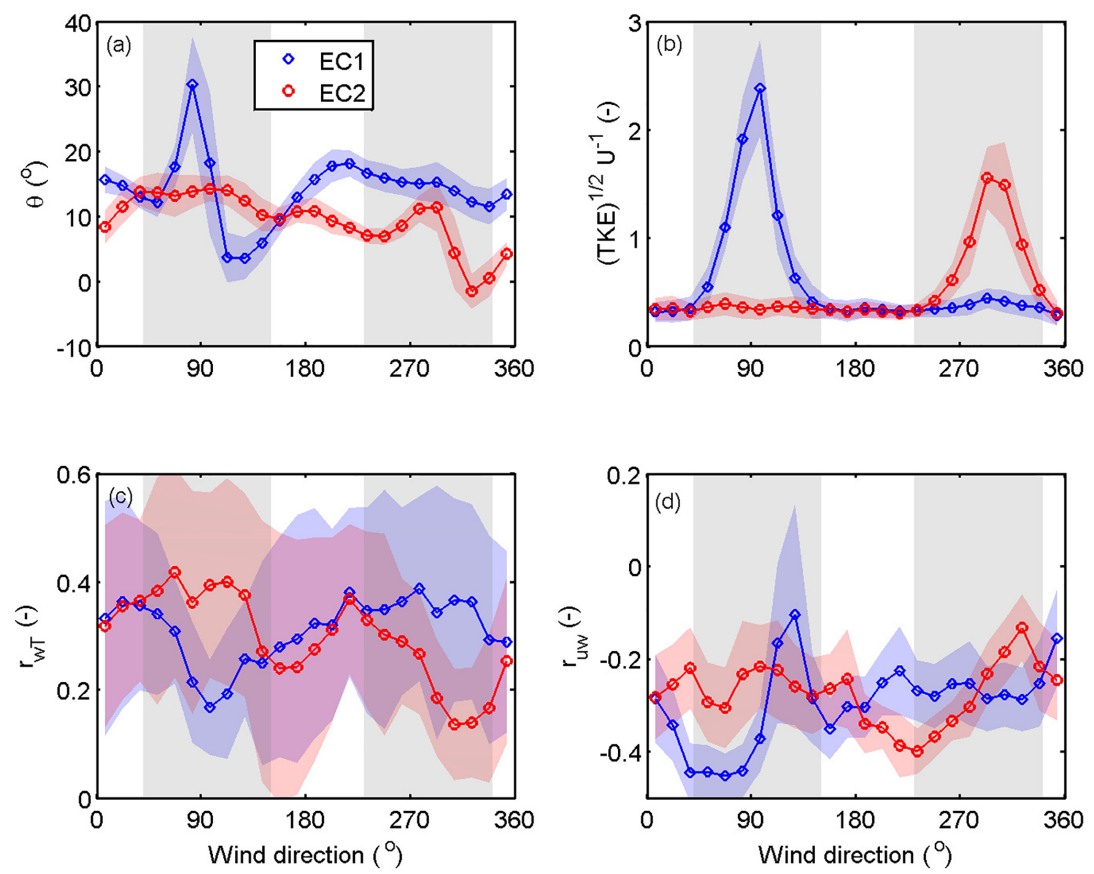

Figure 3. Wind direction dependence of (a) the vertical deflection angle $(\theta)$, (b) normalised turbulent kinetic energy (TKE $\left.{ }^{1 / 2} U^{-1}\right)$, and turbulent transfer efficiencies of (c) heat $\left(r_{w T}\right)$ and (d) momentum $\left(r_{u w}\right)$ from EC1 and EC2 during July 2013 until September 2015 . Only winds speeds $U>1 \mathrm{~m} \mathrm{~s}^{-1}$ and for $r_{w T}|H|>10 \mathrm{~W} \mathrm{~m}^{-2}$ are taken into account. Lines and symbols represent the $15^{\circ}$ bin averages, and the patches $\pm 1 \mathrm{SD}$. The disturbed wind directions (40-150 for EC1 and $230-340^{\circ}$ for EC2) are marked with grey areas.

\subsection{Skewness and kurtosis}

SK is within the limits of good data quality $(-2<\mathrm{SK}<2)$ for all studied variables, excluding $\mathrm{CO}_{2}$ (Fig. 7, Table 1). Particularly elevated values in the skewness of $\mathrm{CO}_{2}\left(\mathrm{SK}_{\mathrm{C}}\right)$ are seen during the daytime in directions $150-200^{\circ}$, with the median $\mathrm{SK}_{\mathrm{C}}$ reaching 4 , whereas in other directions the medians are around 1 . The 90 th percentiles can reach as high as 5 in directions $150-200^{\circ}$ as is summarised in Table 1 . A similar elevated pattern can also be seen in the kurtosis of $\mathrm{CO}_{2}\left(K_{\mathrm{C}}\right)$ with the median values reaching 25 , indicating spiky behaviour in $\mathrm{CO}_{2}$ (Fig. A1). These elevated values are only seen during the daytime, so these must relate to the daily activities emitting $\mathrm{CO}_{2}$ and/or prevailing meteorological conditions. The same can clearly be seen from the diurnal variability of both $\mathrm{SK}_{\mathrm{C}}$ and $K_{\mathrm{C}}$ shown in Fig. 8 for summer months from June till August. Same behaviour is also seen in other months (not shown). While for directions 150-200 elevated values for both statistical variables are seen, in other directions the diurnal variability of $\mathrm{SK}_{\mathrm{C}}$ and $K_{\mathrm{C}}$ is relatively flat, with the 90th percentiles remaining mostly below 2 and 6 , respectively.

In the direction of elevated $\mathrm{SK}_{\mathrm{C}}$ and $K_{\mathrm{C}}$, both variables start to increase in the morning at 06:00 $(\mathrm{UTC}+2)$, corresponding with the increase in both road traffic and atmospheric instability observed in Helsinki (Kurppa et al., 2015). Two clear peaks in $\mathrm{SK}_{\mathrm{C}}$ and $K_{\mathrm{C}}$ are seen around noon and af- ternoon between 15:00 and 19:00. The first peak corresponds with maxima mixing conditions, and the second peak with afternoon rush hour. Commonly, at the time of morning rush hour (07:00-09:00) the atmospheric mixing is still relatively weak and pollutants from the street level are not necessarily as easily transported to the measurement level (Contini et al., 2012; Kurppa et al., 2015). Previously, a skewed distribution of turbulent velocity components within and just above the street canyon has been linked to street canyon vortexes causing sweeps and ejections (Oikawa and Meng, 1995). This could also be a potential explanation for the high $\mathrm{SK}_{\mathrm{C}}$ and $K_{\mathrm{C}}$ values in directions $150-200^{\circ}$ since these directions correspond with wind blowing perpendicular to the streets in the grid type street network in Helsinki. Previous studies utilising large-eddy simulation have also shown how street canyon ventilation and sweeps increase in more unstable conditions (Gronemeier et al., 2017; Raupach et al., 2015), which is in accord with our results related to the timing of the maximum $\mathrm{SK}_{\mathrm{C}}$ and $K_{\mathrm{C}}$. But the effect of meteorological background conditions cannot be ruled out since the directions with elevated $\mathrm{SK}_{\mathrm{C}}$ and $K_{\mathrm{C}}$ correspond with flow coming from the sea, which can further modify the flow and skewed distribution of $\mathrm{CO}_{2}$ concentration. High skewness values of $\mathrm{CO}_{2}$ data have previously been connected to local-scale anthropogenic sources (Kotthaus and Grimmond, 2012). At the hotel building, small ventilation units are located $9 \mathrm{~m}$ below the measurement systems in the north-eastern, north-western 

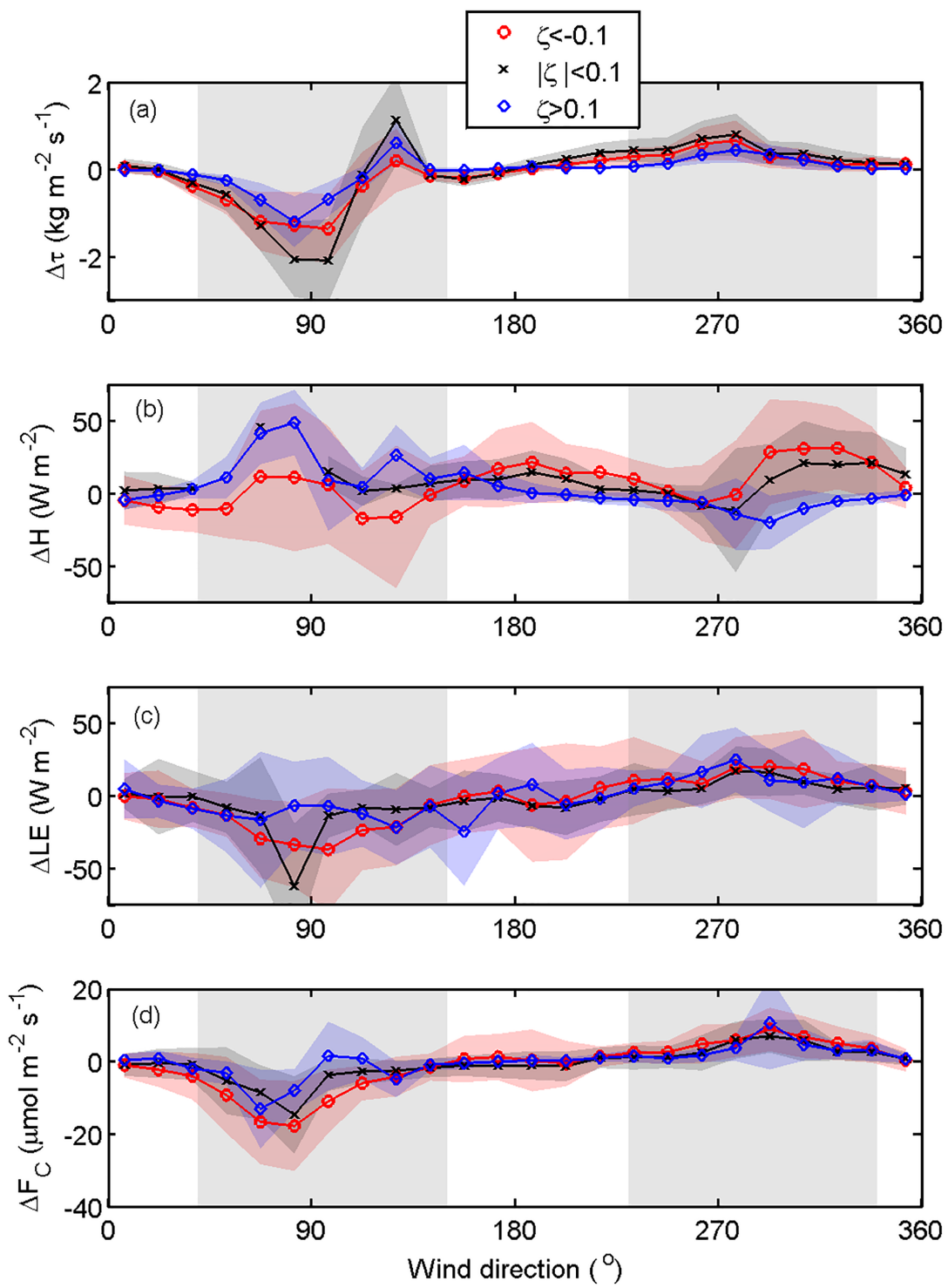

Figure 4. Wind direction dependence of the differences in the (a) momentum $(\tau),(\mathbf{b})$ sensible $(H)$ and $(\mathbf{c})$ latent heat $(\mathrm{LE})$, and $(\mathbf{d}) \mathrm{CO}_{2}$ $\left(F_{\mathrm{C}}\right)$ fluxes between the two EC systems (EC1-EC2). Differences are calculated for the whole measurement period, and data are separated into different stability classes (unstable $(\zeta<-0.1)$, stable $(\zeta>0.1)$ and neutral $(|\zeta|<0.1)$ ) based on the stability parameter $\zeta$. Lines and symbols represent the $15^{\circ}$ bin averages, and the shaded areas $\pm 1 \mathrm{SD}$. The neglected wind directions $\left(40-150^{\circ}\right.$ for EC1 and $230-340^{\circ}$ for EC2) are marked with grey areas.

and south-western corners, but, as these do not match the directions $150-200^{\circ}$ and systematic signals are seen in both $\mathrm{EC} 1$ and $\mathrm{EC} 2$, these units cannot be responsible for the increased $\mathrm{SK}_{\mathrm{C}}$ and $K_{\mathrm{C}}$. Furthermore, these local-scale sources have been connected to increased fluxes $F_{\mathrm{C}}$ and $H$ as well as decreased LE, whereas in our case slightly higher flux values are only seen in $F_{\mathrm{C}}$ in unstable conditions in directions $150-200^{\circ}$ (Fig. B1). Notwithstanding the reason for the elevated $\mathrm{SK}_{\mathrm{C}}$ and $K_{\mathrm{C}}$, filtering $F_{\mathrm{C}}$ data based on these variables would remove realistic flux values, and therefore they should be used with caution in post-processing of $\mathrm{CO}_{2}$ fluxes.
At the same time, with increased $\mathrm{SK}_{\mathrm{C}}$ and $K_{\mathrm{C}}$ in the southern direction, the flux stationarity of $F_{\mathrm{C}}$ remains below 0.2 , which is considered to constitute high-quality flux data (Fig. 9). Thus, applying only the stationarity criteria with either a $30 \%$ or a $60 \%$ limit but no skewness or kurtosis criteria would leave most of the data for further data analysis. The most non-stationary variable is the latent heat flux, with 90th percentiles systematically over 1 in all directions and hours as measured by both setups. $\mathrm{FS}_{h}$ gets slightly greater values with $\mathrm{EC} 1$ than $\mathrm{EC} 2$, with the former having median values of 0.24 (90th percentile: 1.24) in summer and 0.39 (1.56) in winter, and the latter 0.21 (1.08) and 0.39(1.53), respec- 

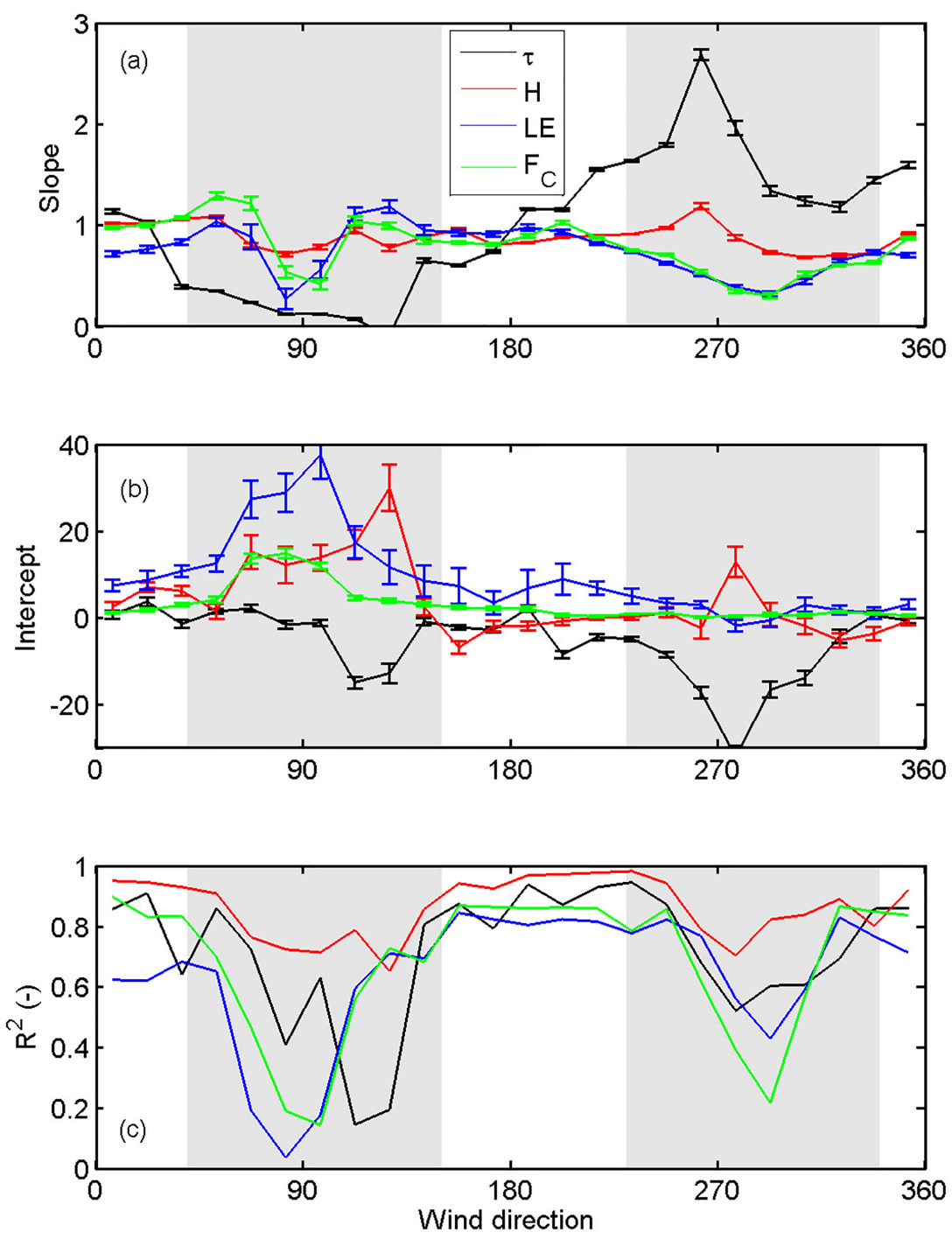

Figure 5. Wind direction dependence of the (a) slope, (b) intercept $\left(\mathrm{kg} \mathrm{m}^{-2} \mathrm{~m}^{-1}, \mathrm{~W} \mathrm{~m}^{-2}, \mu \mathrm{mol} \mathrm{m}^{-2} \mathrm{~s}^{-1}\right)$ and (c) squared coefficient of determination $\left(R^{2}\right)$ of the linear least square fit of momentum $(\tau)$, sensible $(H)$ and latent heat $(\mathrm{LE})$, and $\mathrm{CO}_{2}\left(F_{\mathrm{C}}\right)$ fluxes between the two EC systems $(E C 2=$ slope $\cdot$ EC1 + intercept $)$ during July 2013 until September 2015 . The neglected wind directions $\left(40-150^{\circ}\right.$ for EC1 and $230-340^{\circ}$ for EC2) are marked with grey areas.

tively. Interestingly, relatively large flux stationary values of momentum flux are seen both by day and night. Usually, the momentum flux is least filtered based on the stationarity criteria, but in our case, due to the complex measurements location, relatively large data proportions would be filtered away. The median values are $0.27(0.69)$ in summer and $0.17(0.51)$ in winter for $\mathrm{EC} 1$, which is fairly similar to $\mathrm{EC} 2$, with median values of $0.28(0.67)$ and $0.19(0.45)$. Despite the similar magnitude quartile values, EC1 gets greater values in directions $190-360^{\circ}$ and EC2 symmetrically in directions $0-180^{\circ}$.

\subsection{Atmospheric spectra}

More information about the similarity/dissimilarity of the two EC systems can be obtained via spectral analysis
(Fig. 10). The largest differences outside the flow distortion areas can be seen in the cospectrum of momentum flux with similar contribution only at $n=0.02-0.1$ between the two systems (Fig. 10a). With EC1, more contribution is seen at larger eddies, and in the inertial subrange $(n=0.1-0.4)$ the decay is faster than with EC2. A possible explanation for the higher-energy, larger eddies is the building wake effect. With both systems, negative contributions to the total momentum flux are seen at normalised frequencies $>0.5$, which are likely to be related to the measurement location being on top of a tower. This supports the previous findings that velocity components are more impacted by the measurement location than the scalars. Similarly to $\tau$, in the cospectra of $F_{\mathrm{C}}$ the larger eddies (below normalised frequency 0.03 ) 
Table 1. Medians and percentile values (10th, 50th and 90th) of skewness (SK), kurtosis $(K)$ and flux stationarity (FS) of vertical wind speed $(w)$, air temperature $(T), \mathrm{CO}_{2}(\mathrm{c})$ and water vapour $(h)$ measured by the two EC setups (EC1 and EC2). Data are separated into summer (June-August) and winter (December-February), and $\mathrm{CO}_{2}$ statistics are differentiated for wind sectors (WD1: 150-200; WD2: the remaining sector). $N$ is the number of data points.

\begin{tabular}{|c|c|c|c|c|c|c|c|c|c|c|c|c|}
\hline EC1 & Season & & $N$ & & SK & & & $K$ & & & FS & \\
\hline \multirow{2}{*}{$w$} & Summer & & 10335 & -0.09 & 0.17 & 0.56 & 3.1 & 3.5 & 4.4 & 0.06 & 0.27 & 0.69 \\
\hline & Winter & & 8042 & -0.13 & 0.12 & 0.42 & 3.1 & 3.5 & 4.2 & 0.03 & 0.17 & 0.51 \\
\hline \multirow{2}{*}{$T$} & Summer & & 10333 & 0.06 & 0.55 & 1.25 & 2.7 & 3.6 & 6.0 & 0.04 & 0.18 & 0.68 \\
\hline & Winter & & 8028 & 0.01 & 0.47 & 1.37 & 3.0 & 4.1 & 7.7 & 0.04 & 0.20 & 0.92 \\
\hline \multirow{4}{*}{$c$} & \multirow{2}{*}{ Summer } & WD1 & 633 & -0.02 & 2.07 & 5.15 & 3.4 & 11.7 & 45.0 & 0.02 & 0.12 & 0.45 \\
\hline & & WD2 & 6695 & -0.45 & 0.39 & 1.45 & 2.6 & 3.5 & 9.0 & 0.01 & 0.09 & 0.42 \\
\hline & \multirow{2}{*}{ Winter } & WD1 & 967 & -0.03 & 1.54 & 5.73 & 2.8 & 8.4 & 50.3 & 0.01 & 0.04 & 0.24 \\
\hline & & WD2 & 4447 & -0.20 & 0.49 & 2.93 & 2.5 & 3.5 & 22.4 & 0.01 & 0.07 & 0.35 \\
\hline \multirow{2}{*}{$h$} & Summer & & 8209 & -1.08 & -0.31 & 0.44 & 2.2 & 3.1 & 5.3 & 0.03 & 0.24 & 1.24 \\
\hline & Winter & & 5397 & -0.51 & 0.06 & 0.62 & 2.0 & 2.6 & 3.7 & 0.05 & 0.39 & 1.56 \\
\hline $\mathrm{EC} 2$ & Season & & $N$ & & SK & & & $K$ & & & FS & \\
\hline \multirow{2}{*}{$w$} & Summer & & 10480 & -0.17 & 0.26 & 0.61 & 3.2 & 3.9 & 5.1 & 0.05 & 0.28 & 0.67 \\
\hline & Winter & & 7702 & 0.00 & 0.26 & 0.49 & 3.2 & 3.8 & 4.6 & 0.03 & 0.19 & 0.45 \\
\hline \multirow{2}{*}{$T$} & Summer & & 10470 & 0.00 & 0.52 & 1.17 & 2.6 & 3.6 & 5.9 & 0.04 & 0.17 & 0.75 \\
\hline & Winter & & 7701 & -0.03 & 0.35 & 1.26 & 3.0 & 4.3 & 8.9 & 0.03 & 0.21 & 1.00 \\
\hline \multirow{4}{*}{$c$} & \multirow{2}{*}{ Summer } & WD1 & 767 & -0.02 & 2.11 & 5.46 & 3.3 & 12.1 & 48.1 & 0.01 & 0.09 & 0.38 \\
\hline & & WD2 & 7617 & -0.44 & 0.43 & 1.67 & 2.6 & 3.6 & 11.0 & 0.01 & 0.07 & 0.36 \\
\hline & \multirow{2}{*}{ Winter } & WD1 & 1346 & -0.08 & 1.73 & 6.23 & 2.7 & 9.2 & 60.2 & 0.00 & 0.03 & 0.13 \\
\hline & & WD2 & 6294 & -0.14 & 0.53 & 3.31 & 2.6 & 3.6 & 25.0 & 0.00 & 0.06 & 0.31 \\
\hline \multirow{2}{*}{$h$} & Summer & & 8232 & -1.10 & -0.32 & 0.40 & 2.3 & 3.1 & 5.3 & 0.03 & 0.21 & 1.08 \\
\hline & Winter & & 7593 & -0.50 & 0.06 & 0.61 & 1.9 & 2.6 & 3.6 & 0.05 & 0.39 & 1.53 \\
\hline
\end{tabular}

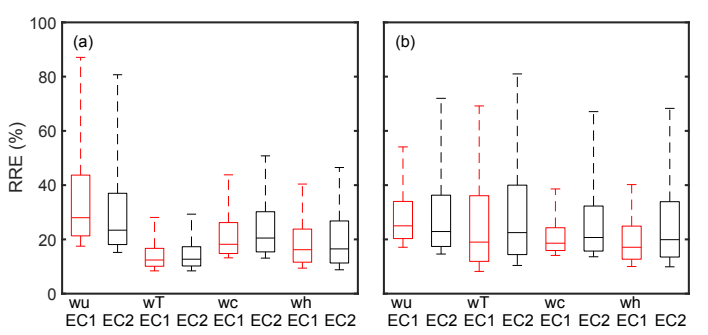

Figure 6. Relative random error (RRE) for (a) daytime (solar elevation angle $>0^{\circ}$ ) and (b) night-time (solar elevation angle $\leq 0^{\circ}$ ) momentum $(w u)$, heat $(w T), \mathrm{CO}_{2}(w c)$ and water vapour $(w h)$ covariances from the two systems EC1 and EC2 outside the flow distortion sectors. Whiskers and boxes represent the 10th, 25th, 50th, 75th and 90th percentiles.

contribute slightly more to the total flux measured by EC1 than EC2 and the energy decaying in the inertial subrange $(n>2)$ is faster than in the case of EC2 (Fig. 10c). Thus, the flux differences seen in $\tau$ and $F_{\mathrm{C}}$ between the two systems are to a large extent caused by the larger eddies rather than small-scale variations. For the temperature flux covariance (Fig. 10e), such differences are not seen, but rather the contribution of different-sized eddies is very similar between the two systems. Atmospheric spectra of all quantities measured by both systems are similar (Fig. 10b, d, f). This indicates different transport mechanisms for temperature and $\mathrm{CO}_{2}$, which has also been found when comparing the transfer efficiencies of the different scalars in this study and in Nordbo et al. (2013) at the same site.

\subsection{Cumulative surface exchanges}

One of the key questions of this study is on how representative a single EC measurement point, in measuring vertical fluxes, can be when the measurements are forced to be conducted close to urban structures, potentially causing a large removal of data due to flow distortion areas. After flow distortion and stationarity filtering, the temporal annual coverages at the continuous measurement site EC1 vary from $24 \%$ to $50 \%$, with $H$ and $F_{\mathrm{C}}$ having mean data coverages of $44 \%$ and $45 \%$ as compared to LE of $31 \%$ (Table 2). The inclusion of the second EC system increases the data coverage substantially, with $H$ having mean coverage of $65 \%$, LE of $45 \%$ and $F_{\mathrm{C}}$ of $69 \%$. The next step is to examine the impact of the different data coverages on the cumulative flux values. 

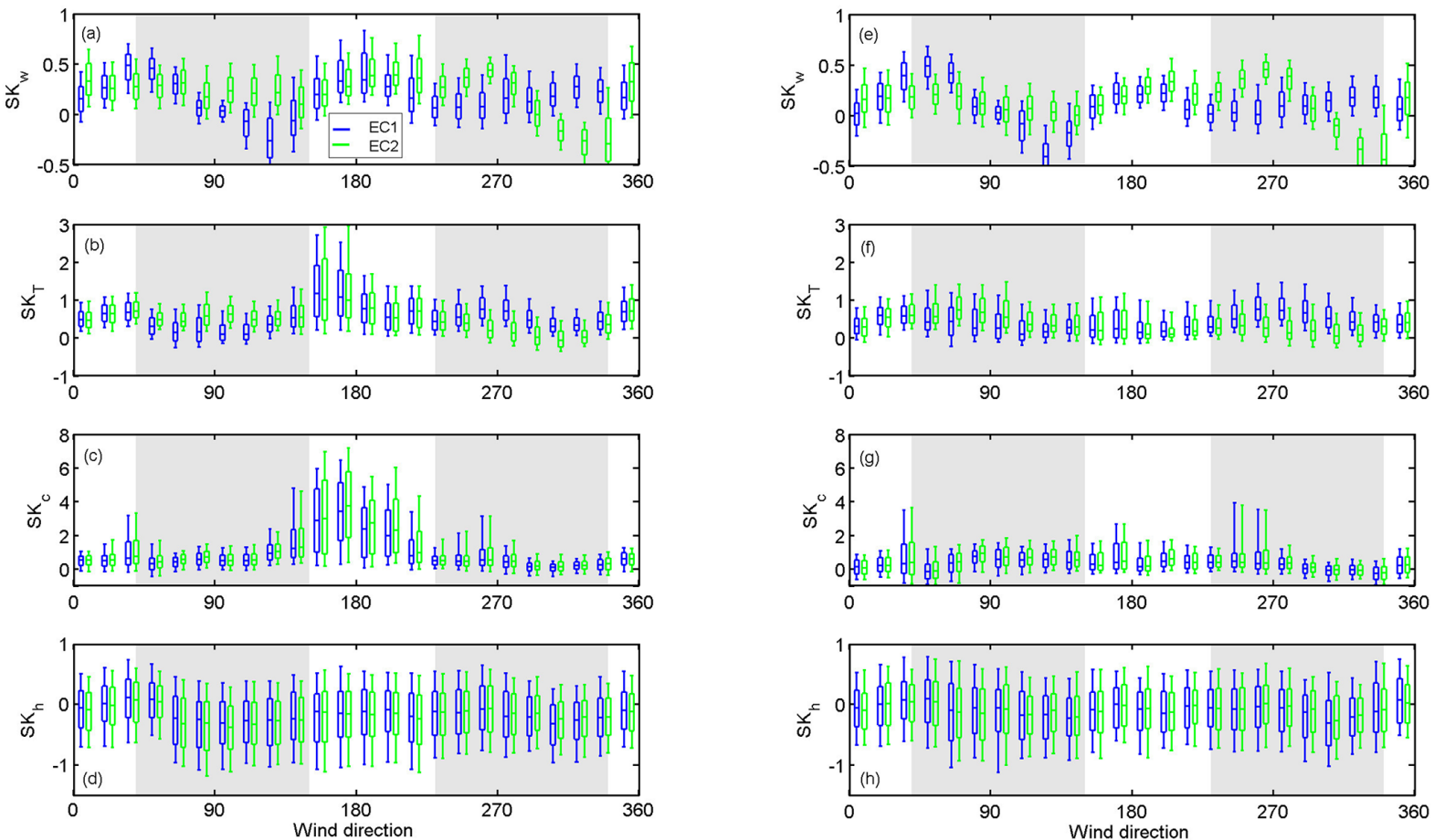

Figure 7. Skewness $(\mathrm{SK})$ of $(\mathbf{a}, \mathbf{e})$ vertical wind speed $(w),(\mathbf{b}, \mathbf{f})$ air temperature $(T),(\mathbf{c}, \mathbf{g}) \mathrm{CO}_{2}(c)$ and $(\mathbf{d}, \mathbf{h})$ water vapour $(h)$ as a function of wind direction for hours 06:00-21:00 (a)-(d) and 21:00-06:00 (e)-(h) for EC1 (blue) and EC2 (green) during July 2013 until September 2015. Whiskers and boxes represent the 10th, 25th, 50th, 75th and 90th percentiles.
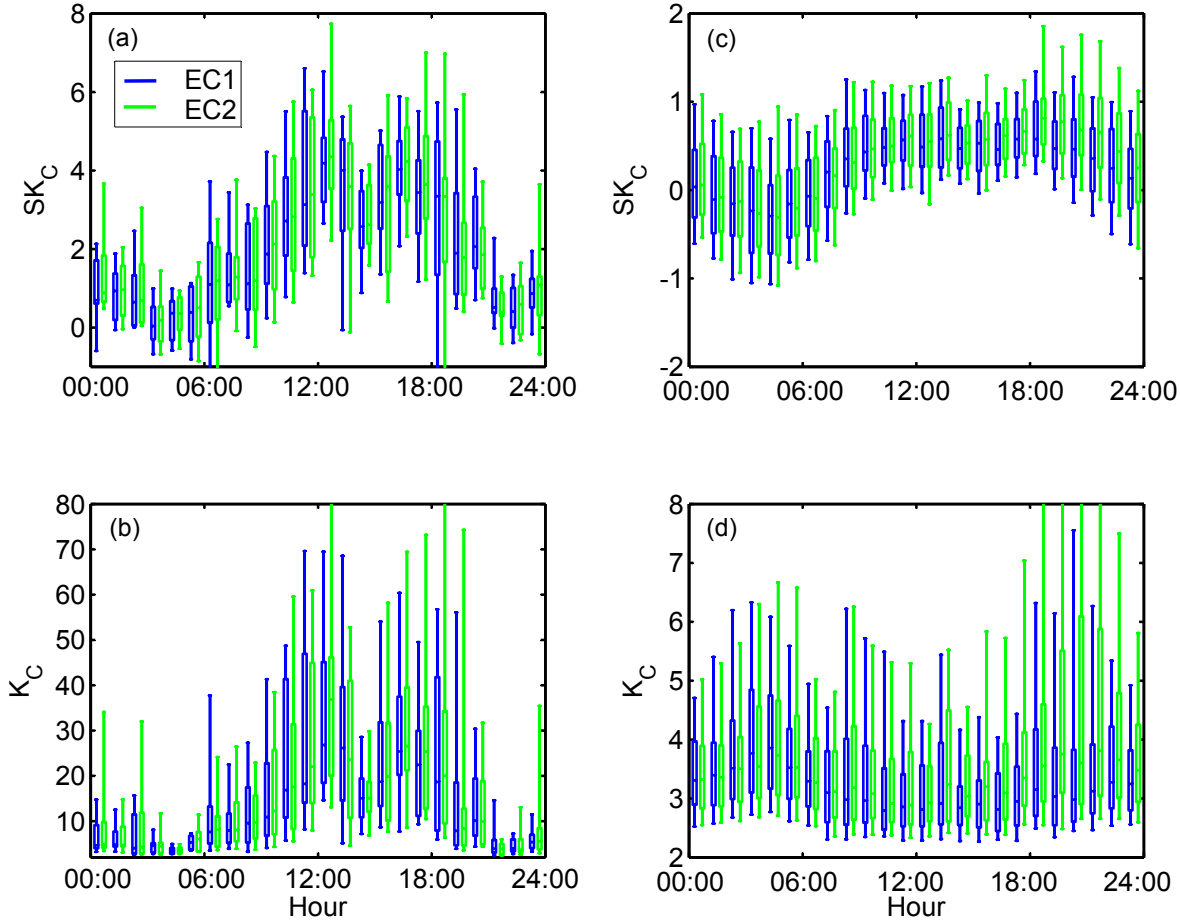

Figure 8. Diurnal variability of skewness (SK) and kurtosis $(K)$ of $\mathrm{CO}_{2}$ for the $150-200^{\circ}$ sector (a, b) and for the other directions (c, d) in summer (June to August). Notice the different $y$ axes on each plot. Whiskers and boxes represent the 10th, 25th, 50th, 75th and 90th percentiles. 

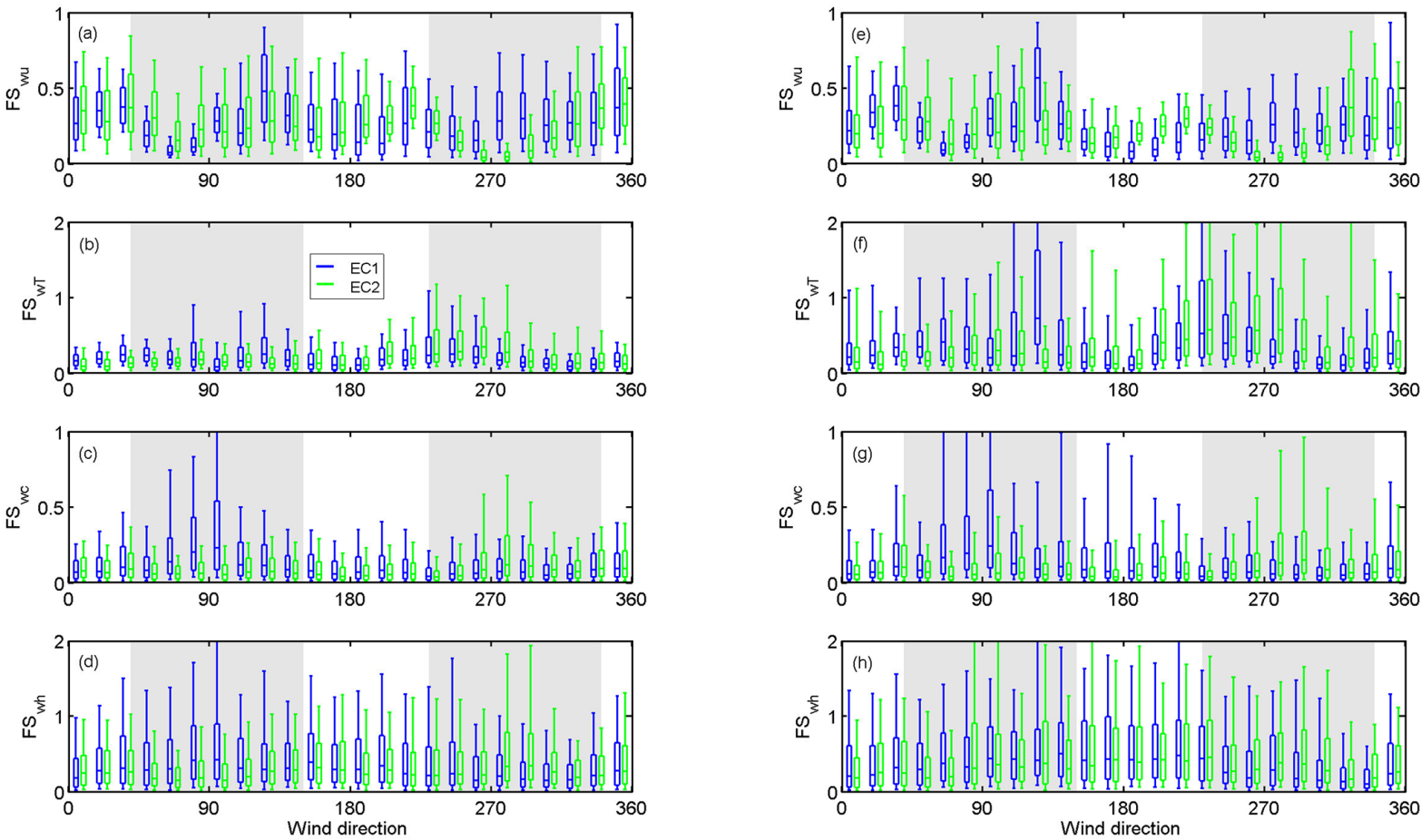

Figure 9. Stationarity (FS) of (a, e) vertical wind speed $(w),(\mathbf{b}, \mathbf{f})$ air temperature $(T),(\mathbf{c}, \mathbf{g}) \mathrm{CO}_{2}(c)$ and $(\mathbf{d}, \mathbf{h})$ water vapour $(h)$ as a function of wind direction for hours 06:00-21:00 (a)-(d) and 21:00-06:00 (e)-(h) for EC1 (blue) and EC2 (green) during July 2013 until September 2015. Whiskers and boxes represent the 10th, 25th, 50th, 75th and 90th percentiles.

The annual cumulative flux values of $\mathrm{CO}_{2}$ and sensible and latent heat calculated for two annual periods (July 2013June 2014 and July 2014-June 2015) using different gapfilling methods are shown in Fig. 11. EC1 and EC2 are gapfilled with their own median cycles using a 3-month period around the month being gap-filled with a separation into workdays and weekends. EC1 + EC2 is a combination of $\mathrm{EC} 1$ and EC2 systems, with data from the first taken in directions $230-340^{\circ}$ and the latter in directions $40-130^{\circ}$, and in other directions the mean of the two systems is calculated. Missing data were furthermore gap-filled in a similar fashion to $\mathrm{EC} 1$ and $\mathrm{EC} 2$. In the case of $F_{\mathrm{C}}, \mathrm{EC} 1+\mathrm{EC} 2$ gives $3 \%-$ $12 \%$ larger cumulative flux values than using only $\mathrm{EC} 1$ or EC2, with an annual mean value of $0.375 \mathrm{kmol} \mathrm{m}^{-2}$, corresponding to $4500 \mathrm{~g} \mathrm{C} \mathrm{m}^{-2}$ (Table 2). This indicates that the resulting error in cumulative carbon fluxes due to the single EC measurement point is up to $12 \%$ when other error sources are ignored. For $H$ and LE, the differences between the combination data set and EC1 and EC2 are up to $5.3 \%$ and $8.1 \%$, respectively, with larger cumulative values obtained with $\mathrm{EC} 1+\mathrm{EC} 2$ than the separate instruments. The difference in $F_{C}$ is of the same order of magnitude as what has been observed above a forest site within a separation of $30 \mathrm{~m}$ between two EC systems (Rannik et al., 2006).

If, in addition to the flux stationarity, we had used the common limits of $K<1$ and $K>8$ and $|\mathrm{SK}|>2$ to filter out data, the data coverages of the single EC systems would have decreased by $11 \%$ for $F_{\mathrm{C}}$ and $3 \%$ and $1 \%$ for $H$ and LE, respectively (Table 2 ). This would have given a mean cumulative $F_{\mathrm{C}}$ of $0.3445 \mathrm{kmol} \mathrm{m}^{-2}\left(4134 \mathrm{~g} \mathrm{C} \mathrm{m}^{-2}\right)$, which is $3.5 \%$ lower than what was obtained by using a combination of EC1 + EC2 $\left(0.357 \mathrm{kmol} \mathrm{m}^{-2}=4284 \mathrm{~g} \mathrm{C} \mathrm{m}^{-2}\right)$. Thus, using FS, SK and $K$ to filter our flux data will cause $4.5 \%$ lower cumulative $F_{\mathrm{C}}$ than using only FS.

The outcome of our study is that a single EC measurement point can produce reasonable estimations for surface fluxes above relatively homogeneous urban surface, but the next question naturally is how applicable this result is for other urban EC sites. Each urban measurement location is unique; in order to get a final answer, each site should be separately evaluated with more than one measurement setup. Nevertheless, the obtained uncertainties from this study can be used as a first approximation for urban EC measurements in the same way as the few two- or multiple-tower studies made in vegetated ecosystems are used to give general guidelines for the uncertainties.

\section{Conclusions}

In this study, simultaneous measurements from two EC systems were compared over the highly built-up Helsinki city centre. The identical systems were located symmetrically on 

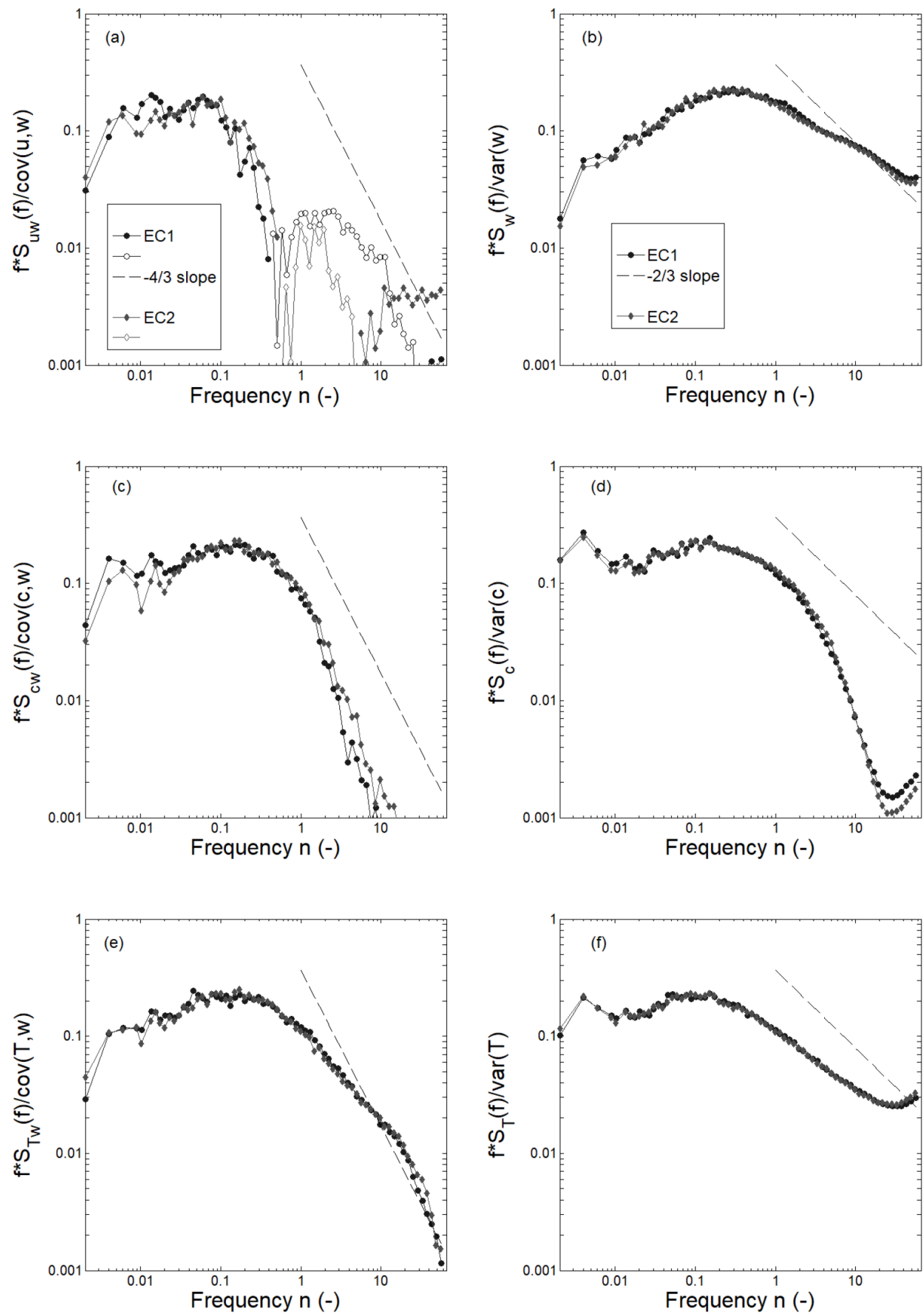

Figure 10. Cospectra (a, $\mathbf{c}, \mathbf{e})$ and spectra $(\mathbf{b}, \mathbf{d}, \mathbf{e})$ of wind $\left(u\right.$ and $w$ component, respectively), $\mathrm{CO}_{2}$ concentration and air temperature $(T)$ as measured with the two EC systems for the undisturbed wind directions during July $2014\left(2.5<U<4 \mathrm{~m} \mathrm{~s}^{-1}\right.$, solar radiation $\left.>10 \mathrm{~W} \mathrm{~m}{ }^{-2}\right)$. Solid symbols indicate positive and open symbols indicate negative contributions of the particular normalised frequency $n(n=f(z-d) / U)$. The $-4 / 3$ and $-2 / 3$ slopes are those predicted by Kolmogorov. 

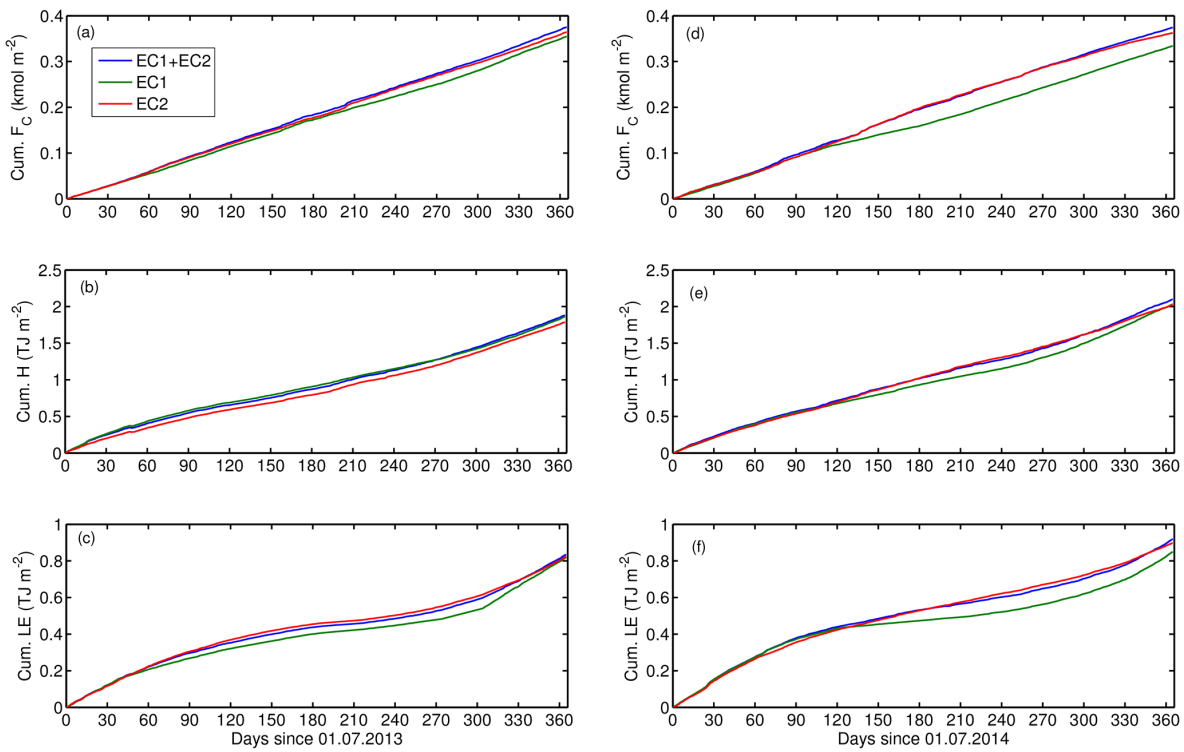

Figure 11. Annual cumulative fluxes of $(\mathbf{a}, \mathbf{b}) \mathrm{CO}_{2}\left(F_{\mathrm{C}}\right),(\mathbf{b}, \mathbf{e})$ sensible $(H)$ and $(\mathbf{c}, \mathbf{f})$ latent heat (LE) for different data sets during July 2013-June 2014 (a)-(c) and July 2014-June 2015 (d)-(f). 1 July. EC1 + EC1 consists of EC1 measurements for the sector 230-340 ${ }^{\circ}$ EC2 measurements for the sector $40-150^{\circ}$ and the average of the two systems outside the flow distortion sectors $\left(40-150^{\circ}\right.$ for EC1 and $230-340^{\circ}$ for EC2). The gap filling of each time series is done based on the diurnal variations over a 3-month period around the month, with working days being gapped separately from weekends and holidays.

Table 2. Gap-filled cumulative (cum) vertical flux values and percentage of data (\%) being gap-filled for two separate years. Fluxes are filtered using either only stationarity $(\mathrm{FS}<0.3)$ or stationarity, kurtosis $(K<1$ or $K>8)$ and skewness $(|\mathrm{SK}|>2) . F_{\mathrm{C}}$ : $\mathrm{CO}_{2}$ flux; $H$ : sensible heat flux; and LE: latent heat flux. See Fig. 11 caption for details for EC1 + EC2, EC1 and EC2.

\begin{tabular}{|c|c|c|c|c|c|c|c|c|}
\hline Period & Flux & Filtering & $\begin{array}{r}\mathrm{EC} 1+\mathrm{EC} 2 \\
\text { cum }\end{array}$ & $(\%)$ & $\begin{array}{l}\text { EC1 } \\
\text { cum }\end{array}$ & $(\%)$ & $\begin{array}{l}\text { EC2 } \\
\text { cum }\end{array}$ & (\%) \\
\hline \multirow{3}{*}{ 7/2013-6/2014 } & $F_{\mathrm{C}}\left(\mathrm{kmol} \mathrm{m}^{-2}\right)$ & \multirow{3}{*}{ FS } & 0.375 & 33.0 & 0.355 & 60.1 & 0.364 & 50.2 \\
\hline & $H\left(\mathrm{TJ} \mathrm{m}^{-2}\right)$ & & 1.880 & 37.4 & 1.861 & 55.6 & 1.786 & 59.2 \\
\hline & $\mathrm{LE}\left(\mathrm{TJ} \mathrm{m}^{-2}\right)$ & & 0.835 & 56.1 & 0.819 & 72.9 & 0.824 & 73.6 \\
\hline \multirow{3}{*}{$7 / 2014-6 / 2015$} & $F_{\mathrm{C}}\left(\mathrm{kmol} \mathrm{m}^{-2}\right)$ & \multirow{3}{*}{ FS } & 0.374 & 29.8 & 0.334 & 59.1 & 0.363 & 51.4 \\
\hline & $H\left(\mathrm{TJ} \mathrm{m}^{-2}\right)$ & & 2.100 & 32.5 & 2.033 & 54.1 & 2.024 & 54.3 \\
\hline & $\mathrm{LE}\left(\mathrm{TJ} \mathrm{m}^{-2}\right)$ & & 0.919 & 54.3 & 0.850 & 75.6 & 0.898 & 69.9 \\
\hline \multirow{3}{*}{ 7/2013-6/2014 } & $F_{\mathrm{C}}\left(\mathrm{kmol} \mathrm{m}^{-2}\right)$ & \multirow{3}{*}{ FS, $K, \mathrm{SK}$} & 0.357 & 47.1 & 0.343 & 68.8 & 0.346 & 62.8 \\
\hline & $H\left(\mathrm{TJ} \mathrm{m}^{-2}\right)$ & & 1.918 & 41.6 & 1.897 & 59.7 & 1.862 & 62.9 \\
\hline & $\mathrm{LE}\left(\mathrm{TJ} \mathrm{m}^{-2}\right)$ & & 0.827 & 57.2 & 0.814 & 73.5 & 0.816 & 74.3 \\
\hline \multirow{3}{*}{$7 / 2014-6 / 2015$} & $F_{\mathrm{C}}\left(\mathrm{kmol} \mathrm{m}^{-2}\right)$ & \multirow{3}{*}{$\mathrm{FS}, K, \mathrm{SK}$} & 0.367 & 44.5 & 0.320 & 68.1 & 0.365 & 64.8 \\
\hline & $H\left(\mathrm{TJ} \mathrm{m}^{-2}\right)$ & & 2.127 & 35.2 & 2.058 & 56.7 & 2.082 & 56.3 \\
\hline & $\mathrm{LE}\left(\mathrm{TJ} \mathrm{m}^{-2}\right)$ & & 0.913 & 54.9 & 0.839 & 76.0 & 0.896 & 70.3 \\
\hline
\end{tabular}

either side atop a tower structure with building masonry located in between. Data were identically analysed. This allowed us to examine the sensitivity of a single-point EC system in measuring the vertical fluxes of momentum, sensible and latent heat, and carbon dioxide, and to understand what the implications are of the non-ideal measurement location and resulting data removal of the studied fluxes.
The flow distortion areas (40-150 and $\left.230-340^{\circ}\right)$ of the two EC systems caused by the building masonry are most clearly distinguishable from wind-normalised TKE. These areas together with a stationarity limit of $30 \%$ resulted in data coverage ranging $24 \%-50 \%$ when measured with a single system. Outside the flow distortion areas, momentum flux is the most sensitive of all fluxes for the measurement location and flow modifications caused by the masonry, with 
random uncertainties being around $25 \%$. With scalar fluxes these remained between $18 \%$ and $22 \%$. Most of the differences in momentum fluxes are due to larger-scale eddies as revealed by spectral analysis indicating larger-scale structures being responsible for the observed differences between these two fluxes.

The two systems had a separation distance of $10 \mathrm{~m}$, indicating that both systems were measuring virtually the same source area, and therefore the differences are considered to be caused by variations in flux fields due to the complex surroundings and measurement platform. Despite the measurement location of the EC systems being non-ideal from the point of view of flow distortion, the possible bias caused by a single measurement point is less than $12 \%$ for $\mathrm{CO}_{2}$ flux and less than $5 \%$ and $8 \%$ for sensible and latent heat fluxes, respectively. In general, the results show how a single-point EC measurement can be representative for flux estimates in Helsinki city centre despite the relatively large flow distortion area removing $27 \%$ of the data. This result is naturally location-specific for this highly built-up site with vegetation cover comprising only $22 \%$ and a relatively homogeneous roof level (Nordbo et al., 2013). The same result could be considered to apply also in other dense city centres with similar relatively homogeneous surface characteristics.

We furthermore show that kurtosis and skewness of concentration measurements, common variables used to flag EC data over vegetated surroundings, are not reasonable measures to filter $\mathrm{CO}_{2}$ flux data in dense urban environment due to the combined effect of temporally varying traffic network, meteorological conditions and characteristics of the upwind source area causing natural spikiness in the $\mathrm{CO}_{2}$ data. Flux stationarity is not impacted in a similar fashion and is therefore considered to be more suitable for filtering $\mathrm{CO}_{2}$ flux data in urban areas. The usage of all three variables to filter out $\mathrm{CO}_{2}$ flux data will cause an underestimation of $4.5 \%$ in annual cumulative carbon fluxes.

Our results are the first from urban areas to characterise the representativeness of single-point EC flux measurements in a densely built urban environment using a combination of two EC systems located close to each other. The related uncertainties are of the same order of magnitude as observed above vegetated ecosystems. The obtained values can be used as a rule of thumb when evaluating in general the representativeness of urban EC measurements used to estimate direct vehicular and building emissions of greenhouse gases and air pollutants. We point out how particular attention should be paid to the data quality control procedures commonly used above vegetated surfaces.

Data availability. Data sets used in the data analysis will be saved to and can be freely downloaded from https://avaa.tdata.fi/web/ smart/smear/ (last access: 1 October 2018). 


\section{Appendix A}
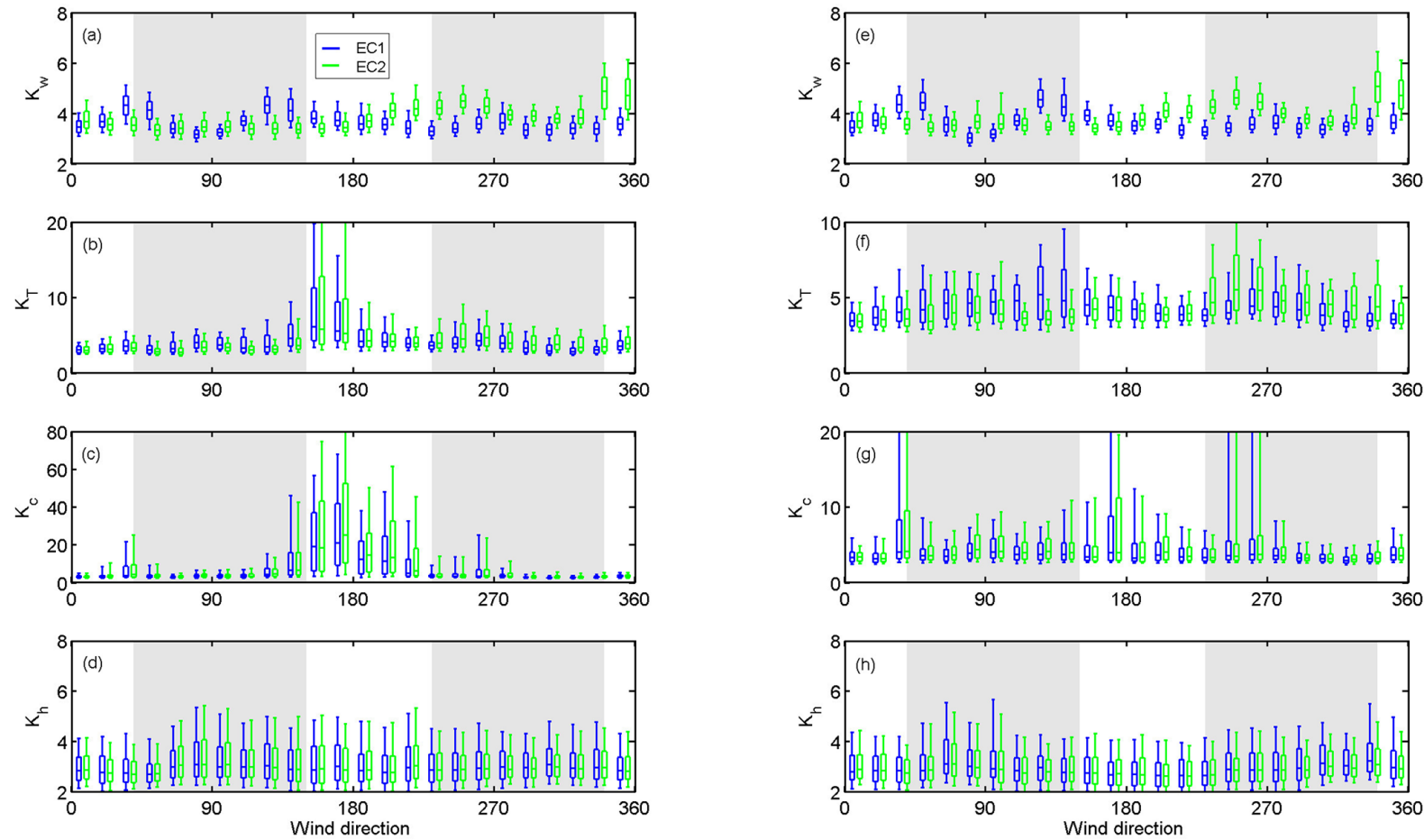

Figure A1. Kurtosis $(K)$ of (a, e) vertical wind speed $(w),(\mathbf{b}, \mathbf{f})$ air temperature $(T),(\mathbf{c}, \mathbf{g}) \mathrm{CO}_{2}(c)$ and $(\mathbf{d}, \mathbf{h})$ water vapour $(w)$ as a function of wind direction for hours 06:00-21:00 (a)-(d) and 21:00-06:00 (e)-(h) for EC1 (blue) and EC2 (green) during July 2013 until September 2015. Whiskers and boxes represent the 10th, 25th, 50th, 75th and 90th percentiles. 


\section{Appendix B}
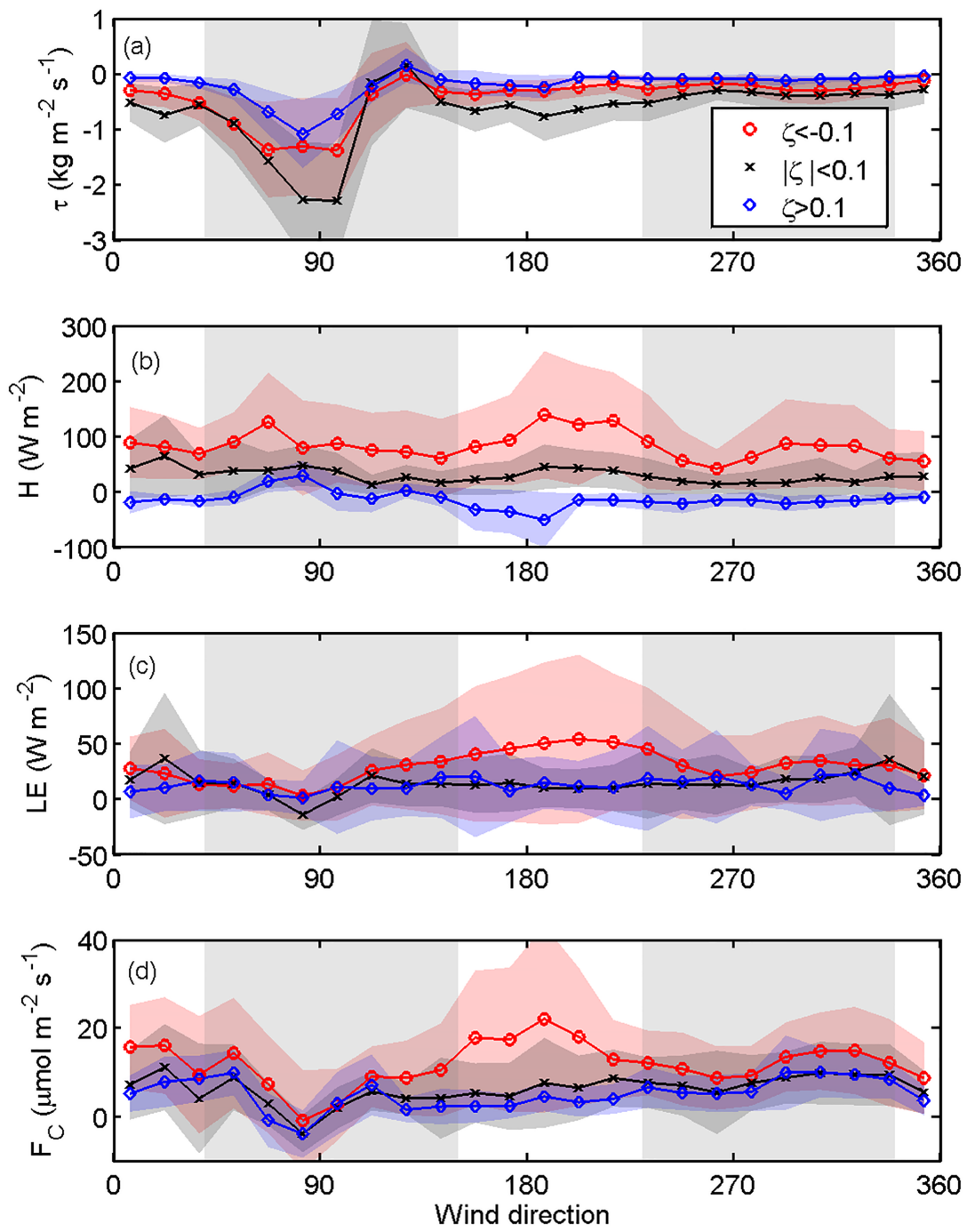

Figure B1. Wind direction dependence of (a) momentum $(\tau)$, (b) sensible $(H)$ and (c) latent heat $(\mathrm{LE})$, and $(\mathbf{d}) \mathrm{CO}_{2}\left(F_{\mathrm{C}}\right)$ fluxes for EC1. The statistics are calculated for the whole measurement period, and data are separated into different stability classes (unstable $(\zeta<-0.1$ ), stable $(\zeta>0.1)$ and neutral $(|\zeta|<0.1)$ ). Lines and symbols represent the $15^{\circ}$ bin averages, and the shaded areas $\pm 1 \mathrm{SD}$. The neglected wind directions $\left(40-150^{\circ}\right.$ for EC1 and $230-340^{\circ}$ for EC2) are marked with grey areas. 
Author contributions. LJ, AK, RDK, TV and CRW planned the measurements; TVK and PR were responsible for the eddy covariance measurements; MK calculated the eddy covariance data; and LJ and ÜR performed further data analysis. All authors participated in writing the manuscript.

Competing interests. The authors declare that they have no conflict of interest.

Acknowledgements. The work was supported by the Academy of Finland project ICOS-Finland and Centre of Excellence programme (grant no. 307331), and Atmospheric Mathematics collaboration (AtMath) of the Faculty of Science, University of Helsinki, and Maa- ja vesitekniikan tuki ry (grant no. 36663). We also thank Sokos Hotel Torni for allowing us to use their building for our EC measurements and Jaakko Kukkonen, Annika Nordbo and Risto Taipale for additional help with the measurements and data analysis.

Edited by: Christian Brümmer

Reviewed by: Olaf Menzer and one anonymous referee

\section{References}

Ao, X., Grimmond, C., Chang, Y., Liu, D., Tang, Y., Hu, P., Wang, Y., Zou, J., and Tan, J.: Heat, water and carbon exchanges in the tall megacity of Shanghai: challenges and results, Int. J. Climatol., 36, 4608-4624, https://doi.org/10.1002/joc.4657, 2016.

Auvinen, M., Järvi, L., Hellsten, A., Rannik, Ü., and Vesala, T.: Numerical framework for the computation of urban flux footprints employing large-eddy simulation and Lagrangian stochastic modeling, Geosci. Model Dev., 10, 4187-4205, https://doi.org/10.5194/gmd-10-4187-2017, 2017.

Barlow, J., Harrison, J., Robins, A., and Wood, C.: A wind-tunnel study of flow distortion at a meteorological sensor on top of the BT Tower, London, UK, J. Wind Eng. Ind. Aerod., 99, 899-907, https://doi.org/10.1016/j.jweia.2011.05.001, 2011.

Billesbach, D.: Estimating uncertainties in individual eddy covariance flux measurements: A comparison of methods and a proposed new method, Agr. Forest Meteorol., 151, 394-405, https://doi.org/10.1016/j.agrformet.2010.12.001, 2011.

Brümmer, B., Lange, I., and Konow, H.: Atmospheric boundary layer measurements at the $280 \mathrm{~m}$ high Hamburg weather mast 1995-2011: mean annual and diurnal cycles, Meteorol. Z., 21, 319-335, https://doi.org/10.1127/0941-2948/2012/0338, 2013.

Christen, A., Coops, N., Crawford, B., Kellett, R., Liss, K., Olchovski, I., Tooke, T., van der Laan, M., and Voogt, J.: Validation of modeled carbon-dioxide emissions from an urban neighborhood with direct eddycovariance measurements, Atmos. Environ., 45, 6057-6069, https://doi.org/10.1016/j.atmosenv.2011.07.040, 2011.

Contini, D., Donateo, A., Elefante, C., and Grasso, F.: Analysis of particles and carbon dioxide concentrations and fluxes in an urban area: correlation with traffic rate and local micrometeorology, Atmos. Environ., 46, 25-35, https://doi.org/10.1016/j.atmosenv.2011.10.039, 2012.
Demuzere, M., Harshan, S., Järvi, L., Roth, M., Grimmond, C., Masson, V., Oleson, K., Velasco, E., and Wouters, H.: Impact of urban canopy models and external parameters on the modelled urban energy balance, Q. J. Roy. Meteor. Soc., 143, 1581-1596, https://doi.org/10.1002/qj.3028, 2017.

Finkelstein, P. and Sims, P.: Sampling error in eddy correlation flux measurements, J. Geophys. Res.-Atmos., 106, 3503-3509, https://doi.org/10.1029/2000JD900731, 2001.

Grimmond, C., Blackett, M., Best, M., J, J. B., Baik, J., Belcher, S., Bohnenstengel, S., Calmet, I., Chen, F., Dandou, A., Fortuniak, K., Gouvea, M., Hamdi, R., Hendry, M., Kawai, T., Kawamoto, Y., Kondo, H., Krayenhoff, E., Lee, S., Loridan, T., Martilli, A., Masson, V., Miao, S., Oleson, K., Pigeon, G., Porson, A., Ryu, Y., Salamanca, F., Shashua-Bar, L., Steeneveld, G., Tombrou, M., Voogt, J., Young, D., and Zhang, N.: The international urban energy balance models comparison project: First results from phase 1, J. Appl. Meteorol., 49, 1268-1292, https://doi.org/10.1175/2010JAMC2354.1, 2010.

Gronemeier, T., Raasch, S., and Ng, E.: Effects of Unstable Stratification on Ventilation in Hong Kong, Atmosphere, 8, 168, https://doi.org/10.3390/atmos8090168, 2017.

Hollinger, D. and Richardson, A.: Uncertainty in eddy covariance measurements and its application to physiological models, Tree Physiol., 25, 873-885, https://doi.org/10.1093/treephys/25.7.873, 2005.

Hollinger, D., Aber, J., Dail, B., Davidson, E., Golt, S. M., Hughes, H., Leclerc, M., Lee, J., Richardson, A., Rodrigues, C., Scott, N., Achuatavarier, D., and Walsh, J.: Spatial and temporal variability in forest-atmosphere $\mathrm{CO}_{2}$ exchange, Glob. Change Biol., 10, 1689-1706, https://doi.org/10.1111/j.13652486.2004.00847.x, 2012.

Järvi, L., Nordbo, A., Junninen, H., Riikonen, A., Moilanen, J., Nikinmaa, E., and Vesala, T.: Seasonal and annual variation of carbon dioxide surface fluxes in Helsinki, Finland, in 2006-2010, Atmos. Chem. Phys., 12, 8475-8489, https://doi.org/10.5194/acp-12-8475-2012, 2012.

Karsisto, P., Fortelius, C., Demuzere, M., Grimmond, C., Oleson, K., Kouznetsov, R., Masson, V., and Järvi, L.: Seasonal surface urban energy balance and wintertime stability simulated using three land-surface models in the highlatitude city Helsinki, Q. J. Roy. Meteor. Soc., 142, 401-417, https://doi.org/10.1002/qj.2659, 2015.

Keogh, S., Mills, G., and Fealy, R.: The energy budget of the urban surface: two locations in Dublin, Ir. Geogr., 4, 1-23, 2012.

Kessomkiat, W., Franssen, H.-J. H., Graf, A., and Vereecken, H.: Estimating random errors of eddy covariance data: An extended two-tower approach, Agr. Forest Meteorol., 171, 203 219, https://doi.org/10.1016/j.agrformet.2012.11.019, 2010.

Kordowski, K. and Kuttler, W.: Carbon dioxide fluxes over an urban park area, Atmos. Environ., 44, 2722-2730, https://doi.org/10.1016/j.atmosenv.2010.04.039, 2010.

Kotthaus, S. and Grimmond, C.: Identification of Microscale Anthropogenic $\mathrm{CO} 2$, heat and moisture sources - Processing eddy covariance fluxes for a dense urban environment, Atmos. Environ., 57, 301-316, https://doi.org/10.1016/j.atmosenv.2012.04.024, 2012.

Kurppa, M., Nordbo, A., Haapanala, S., and Järvi, L.: Effect of seasonal variability and land use on particle number and $\mathrm{CO} 2$ 
exchange in Helsinki, Finland, Urban Climate, 13, 94-109, https://doi.org/10.1016/j.uclim.2015.07.006, 2015.

Lenschow, D., Mann, J., and Kristensen, L.: How long is long enough when measuring fluxes and other turbulence statistics, J. Atmos. Ocean. Tech., 11, 661-673, https://doi.org/10.1175/15200426(1994)011<0661:HLILEW>2.0.CO;2, 1994.

Liu, H. Z., Feng, J. W., Järvi, L., and Vesala, T.: Four-year (20062009) eddy covariance measurements of $\mathrm{CO}_{2}$ flux over an urban area in Beijing, Atmos. Chem. Phys., 12, 7881-7892, https://doi.org/10.5194/acp-12-7881-2012, 2012.

Mccalmont, J. P., Mcnamara, N. P., Donnison, I. S., Farrar, K., and Clifton-Brown, J. C.: An interyear comparison of $\mathrm{CO} 2$ flux and carbon budget at a commercial-scale land-use transition from semi-improved grassland to Miscanthus x giganteus, GCB Bioenergy, 9, 229-245, https://doi.org/10.1111/gcbb.12323, 2017.

Menzer, O., Meiring, W., Kyriakidis, P. C., and McFadden, J. P.: Annual sums of carbon dioxide exchange over a heterogeneous urban landscape through machine learning based gap-filling, Atmos. Environ., 101, 312-327, https://doi.org/10.1016/j.atmosenv.2014.11.006, 2015.

Nordbo, A., Järvi, L., Haapanala, S., Wood, C. R., and Vesala, T.: Fraction of natural area as main predictor of net $\mathrm{CO} 2$ emissions from cities, Geophys. Res. Lett., 39, L20802, https://doi.org/10.1029/2012GL053087, 2012a.

Nordbo, A., Järvi, L., and Vesala, T.: Revised eddy covariance flux calculation methodologies: effect on urban energy balance, Tellus B, 64, 18184, https://doi.org/10.3402/tellusb.v64i0.18184, 2012b.

Nordbo, A., Järvi, L., Haapanala, S., Moilanen, J., and Vesala, T.: Intra-City Variation in Urban Morphology and Turbulence Structure in Helsinki, Finland, Bound.-Lay. Meteorol., 146, 469-496, https://doi.org/10.1007/s10546-012-9773-y, 2013.

Nordbo, A., Karsisto, P., Matikainen, L., Wood, C. R., and Järvi, L.: Urban surface cover determined with airborne lidar at $2 \mathrm{~m}$ resolution - implications for surface energy balance modelling, Urban Climate, 13, 52-72, https://doi.org/10.1016/j.uclim.2015.05.004, 2015.

Oikawa, S. and Meng, Y.: Turbulence characteristics and organized motion in a suburban roughness sublayer, Bound.-Lay. Meteorol., 74, 289-312, https://doi.org/10.1007/BF00712122, 1995.

Peltola, O., Hensen, A., Marchesini, L. B., Helfter, C., Bosveld, F. C., van den Bulk, W. C. M., Haapanala, S., van Huissteden, J., Laurila, T., Lindroth, A., Nemitz, E., Röckmann, T., Vermeulen, A. T., and Mammarella, I.: Studying the spatial variability of methane flux with five eddy covariance towers of varying height, Agr. Forest Meteorol., 214-215, 456-472, https://doi.org/10.1016/j.agrformet.2015.09.007, 2015.
Post, H., Hendricks Franssen, H. J., Graf, A., Schmidt, M., and Vereecken, $\mathrm{H}$.: Uncertainty analysis of eddy covariance $\mathrm{CO}_{2}$ flux measurements for different EC tower distances using an extended two-tower approach, Biogeosciences, 12, 1205-1221, https://doi.org/10.5194/bg-12-1205-2015, 2015.

Rannik, Ü., Kolari, P., Vesala, T., and Hari, P.: Uncertainties in measurement and modelling of net ecosystem exchange of a forest, Agr. Forest Meteorol., 138, 244-257, 2006.

Rannik, Ü., Peltola, O., and Mammarella, I.: Random uncertainties of flux measurements by the eddy covariance technique, Atmos. Meas. Tech., 9, 5163-5181, https://doi.org/10.5194/amt-9-51632016, 2016.

Raupach, M. R., Antonia, R. A., and Rajagopalan, S.: Rough-Wall Turbulent Boundary Layers, Appl. Mech. Rev., 44, 1-25, 1991.

Raupach, M. R., Antonia, R. A., and Rajagopalan, S.: A LargeEddy Simulation Study of Thermal Effects on Turbulence Coherent Structures in and above a Building Array, J. Appl. Meteorol. Clim., 52, 1348-1365, https://doi.org/10.1175/JAMC-D-120162.1, 2015.

Rotach, M. W.: Turbulence close to a rough urban surface part II: Variances and gradients, Bound.-Lay. Meteorol., 66, 75-92, 1993.

Roth, M.: Review of atmospheric turbulence over cities, Q. J. Roy. Meteor. Soc., 126, 941-990, https://doi.org/10.1002/qj.49712656409, 2000.

Schmidt, A., Wrzesinsky, T., and Klemm, O.: Gap filling and quality assessment of $\mathrm{CO}_{2}$ and water vapour fluxes above an urban area with radial basis function neural networks, Bound.-Lay. Meteorol., 126, 389-413, https://doi.org/10.1007/s10546-007-9249-7, 2008.

Stull, R. B.: Introduction to boundary layer meteorology, Springer Netherlands, 1998.

Vesala, T., Järvi, L., Launiainen, S., Sogachev, A., Rannik, Ü., Mammarella, I., Siivola, E., Keronen, P., Rinne, J., Riikonen, A., and Nikinmaa, E.: Surface-atmosphere interactions over complex urban terrain in Helsinki, Finland, Tellus B, 60, 188-199, https://doi.org/10.1111/j.1600-0889.2007.00312.x, 2008.

Vickers, D. and Mahrt, L.: Quality control and flux sampling problems for tower and aircraft data, J. Atmos. Ocean. Tech., 14, 512526, 1997.

Wood, C. R., Lacser, A., Barlow, J. F., Padhra, A., Belcher, S. E., Nemitz, E., Helfter, C., Famulari, D., and Grimmond, C.: Turbulent Flow at $190 \mathrm{~m}$ Height Above London During 2006-2008: A Climatology and the Applicability of Similarity Theory, Bound.Lay. Meteorol., 137, 77-96, https://doi.org/10.1007/s10546-0109516-x, 2010. 